\title{
Experimental and Theoretical Studies on the Corrosion Inhibition of Brass in Hydrochloric Acid by N-(4-((4-Benzhydryl Piperazin-1-yl) Methyl Carbamoyl) Phenyl) Furan-2-Carboxamide
}

\author{
N. Zulfareen (iD, ${ }^{1}$ T. Venugopal, ${ }^{2}$ and K. Kannan ${ }^{2}$ \\ ${ }^{1}$ Department of Chemistry, Mahendra Engineering College, Namakkal 637503, India \\ ${ }^{2}$ Department of Chemistry, Government College of Engineering, Salem 636011, India \\ Correspondence should be addressed to N. Zulfareen; fareensha@gmail.com
}

Received 30 January 2018; Accepted 15 May 2018; Published 2 July 2018

Academic Editor: Flavio Deflorian

Copyright (C) 2018 N. Zulfareen et al. This is an open access article distributed under the Creative Commons Attribution License, which permits unrestricted use, distribution, and reproduction in any medium, provided the original work is properly cited.

\begin{abstract}
The corrosion inhibition effect of N-(4-((4-Benzhydryl piperazin-1-yl) methyl Carbamoyl) Phenyl) Furan-2-Carboxamide (BFC) on brass in $1 \mathrm{M} \mathrm{HCl}$ has been investigated using weight loss method, potentiodynamic polarization, electrochemical impedance spectroscopy (EIS), and cyclic voltammetry (CV). The result reveals that BFC acts as a mixed type corrosion inhibitor with more pronounced effect on anodic domain and the inhibition efficiency of $\mathrm{BFC}$ increases with increase in temperature ranges from $30^{\circ} \mathrm{C}$ to $60^{\circ} \mathrm{C}$. AC impedance implies that $\mathrm{R}_{\mathrm{ct}}$ value of BFC increases with increase in concentration. $\mathrm{CV}$ indicates that the addition of inhibitor controls the oxidation of the copper on the brass metal. The structural confirmation of BFC was carried out by the spectral studies like FT-IR, ${ }^{1} \mathrm{H}$ NMR, ${ }^{13} \mathrm{C}$ NMR, and the molecular weight was confirmed by LC-MS. Surface characterization of brass with BFC was analysed using scanning electron microscope (SEM). Quantum chemical parameter was used to calculate the electronic properties of BFC in order to confirm the correlation between the inhibitor effect and molecular structure of BFC. BFC has more negative charge on nitrogen and oxygen atom, which facilitates the adsorption of BFC on the surface of brass.
\end{abstract}

\section{Introduction}

Copper and its alloys are one of the most important nonferrous materials having a wide range of applications in industries due to its electrical conductivity, thermal conductivity, ease of fabrication, resistance to biofouling, and mechanical properties. Copper and copper based resources are intentionally or unintentionally exposed to acid solutions. However copper and its alloys are corrosion resistance towards the atmosphere and many chemicals due to the formation of cuprous oxide layer, when exposed to the atmosphere. They are susceptible to corrosion problems in acid medium such as dezincification and pitting corrosion [1].

The most important method for corrosion protection is by the addition of organic inhibitors on the brass. Many of the inhibitors are organic compounds containing nitrogen, oxygen, sulphur, Phosphorous, and aromatic rings that cause adsorption on the metal surface [2]. Nowadays the synthesized Mannich base compounds have been of interest in order to obtain efficient corrosion inhibitors since they provide much greater inhibition efficiency compared to corresponding amines and aldehydes. The presence of $\mathrm{C}=\mathrm{N}$ group in Mannich base enhances the adsorption ability and inhibition efficiency.

The present work reports on the anticorrosive behaviour of a Mannich base namely N-(4-((4-Benzhydrylpiperazin-1yl) methyl Carbamoyl) Phenyl) Furan-2-Carboxamide (BFC) for brass in hydrochloric acid solution. The kinetics of dissolution and dezincification mechanism of brass in hydrochloric acid solution was investigated using electrochemical studies. For this purpose electrochemical technique such as potentiodynamic polarization, electrochemical impedance spectroscopy (EIS) and cyclic voltammetry in the presence and absence of BFC were studied [3]. 


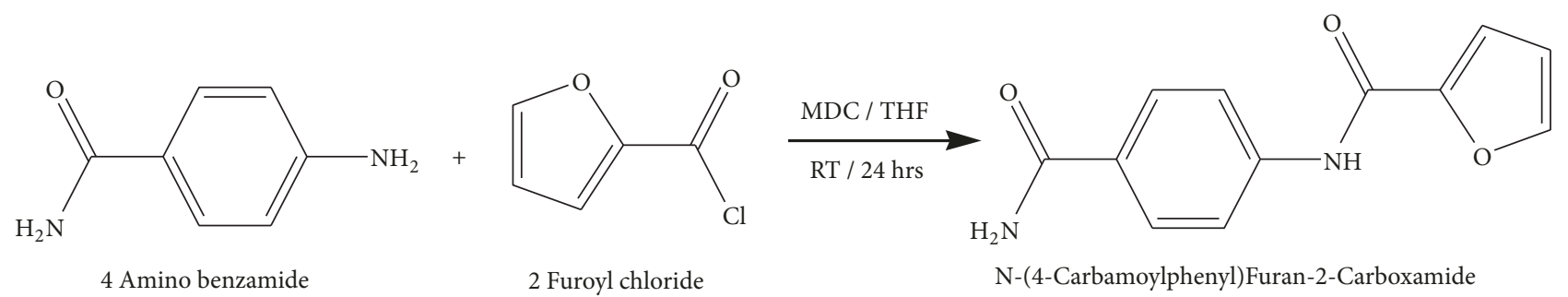

FIgURE 1: Synthesis of CFC.

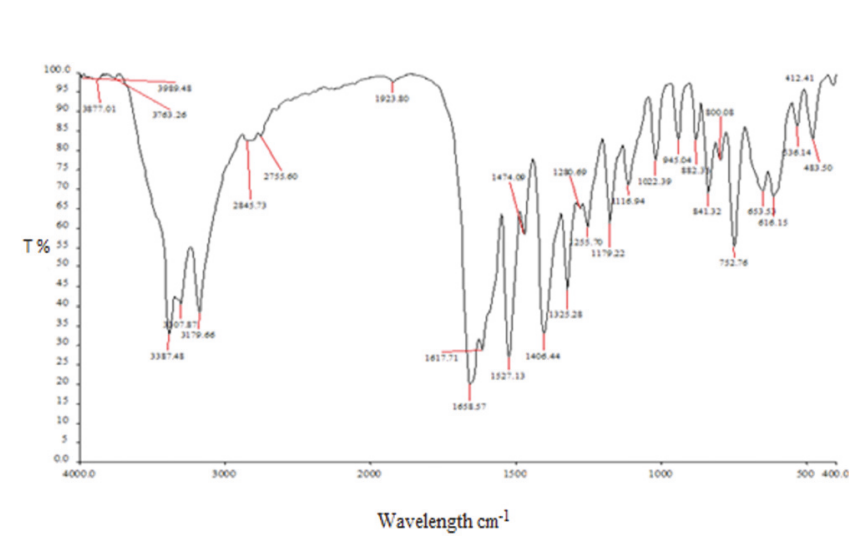

(a) FT-IR spectrum of CFC

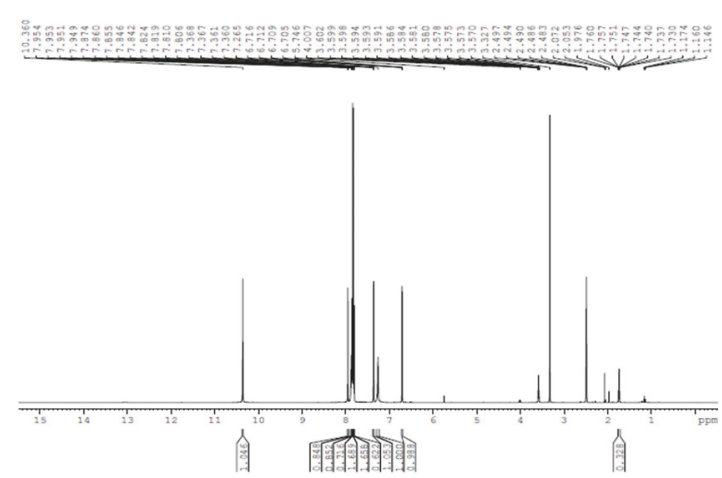

(c) ${ }^{1} \mathrm{H}$ spectrum of CFC

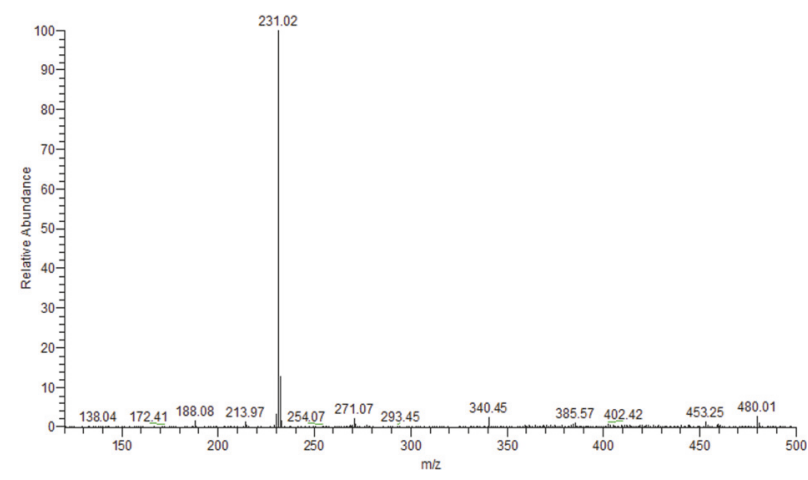

(d) LC-MS spectrum of CFC

Figure 2

It is also aimed to study the quantum chemical parameters and thermodynamic feasibility of the inhibitor using the surface coverage of brass. The interaction of inhibitor (BFC) was correlated with coefficient of their molecular orbitals highest occupied molecular orbital (HOMO), lowest unoccupied molecular orbital (LUMO), energy difference $(\Delta \mathrm{E})$ between $\mathrm{E}_{\mathrm{HOMO}}$ and $\mathrm{E}_{\mathrm{LUMO}}$, atomic charges, and dipole moments. The coordination of ligand to the surface of metal was confirmed by FT-IR. The characterization of BFC was further confirmed by NMR and LC-MS.

\section{Experiment}

2.1. Synthesis of CFC. N-(4-Carbamoylphenyl)Furan-2Carboxamide (CFC) was prepared by a procedure similar to that reported in the literature; 4 -Amino benzamide $(3.00 \mathrm{~g}$,
$0.0220 \mathrm{~mol}$ ) and 2-furoyl chloride $(3.428 \mathrm{~g}, 0.0264 \mathrm{~mol})$ were dissolved in mixture of MDC (70 ml) and THF (25 ml). Triethylamine $(7.77 \mathrm{~g})$ was added, and the mixture was stirred in the presence of nitrogen atmosphere for 24 hours. The reaction mixture was washed with water, filtered, and dried over high vacuum pump. The CFC was characterized by spectral techniques like FT-IR, NMR, and LC-MS. Figure 1 represents the synthesis of CFC.

2.2. Characterization of CFC. Yeild 93\%, white solid, m.p.186$190^{\circ} \mathrm{C}$., IR (KBr, vmax cm ${ }^{-1}$; 3387, 3179(NH, St, Amide), 1658 (C=O), 1617 (NH, Bend, Amide), 1400 (CN, Amide), 1474, 1527 (C=C), 1179 (C-O, furan), 841 (CH, Ar,oop). ${ }^{1} \mathrm{H}$ NMR (400 MHz, DMSO-d $\left.{ }_{6}\right) \mathrm{d}(\mathrm{ppm}): 6.71(1 \mathrm{H}$, Furan $), 7.36(1 \mathrm{H}$, furan), 7.80-7.84 (4H), 7.85-7.87 (2H, Amide), 7.95 (1H, furan), 10.36 (1H, Amide). ${ }^{13} \mathrm{C}$ NMR $(400 \mathrm{MHz}$, DMSO-d 6 ) d(ppm): 


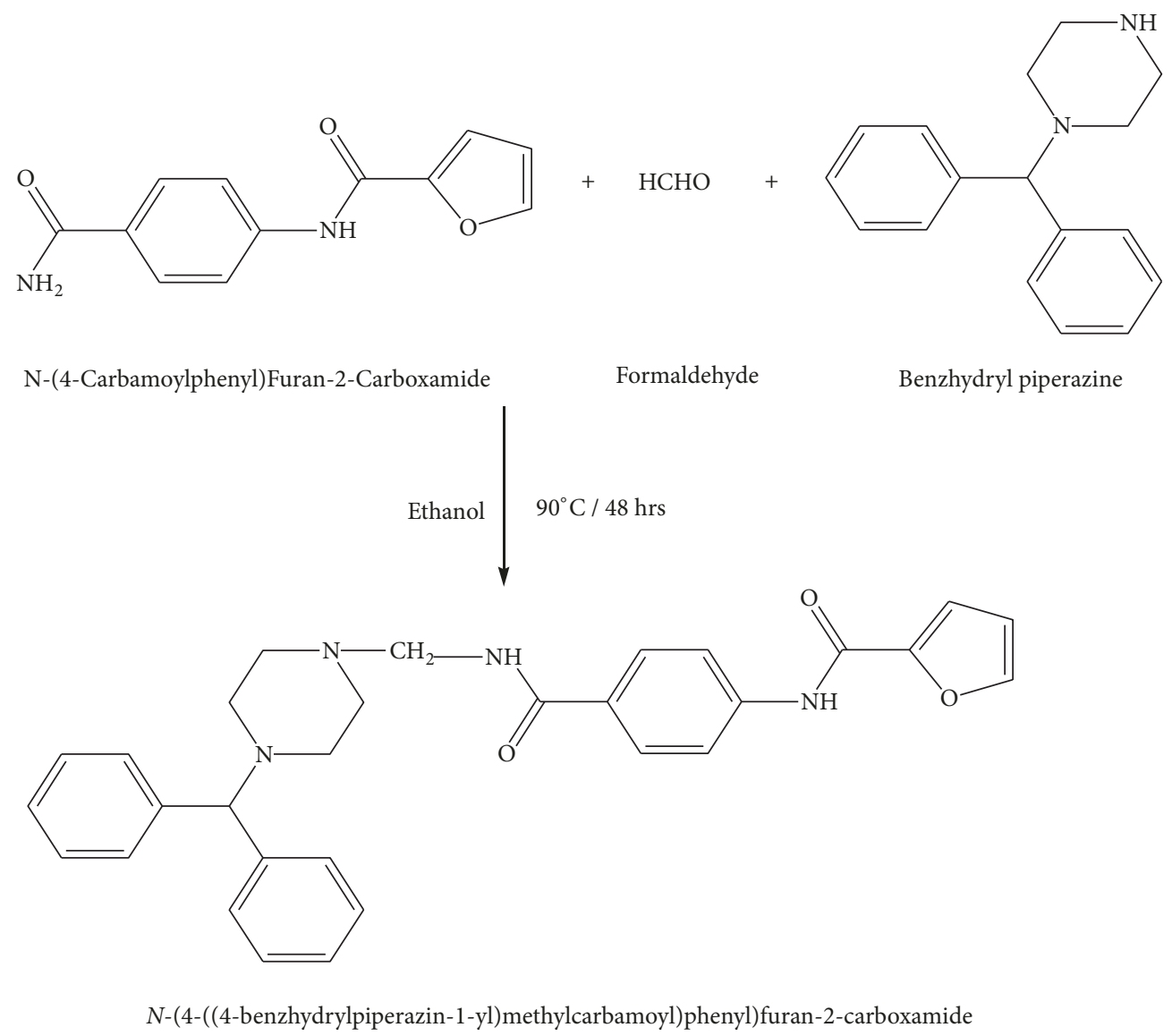

FIGURE 3: Synthesis of BFC.

$\delta$ 112.1, 115.0, 119.2, 128.1, 129.1, 141.1, 145.0, 147.2, 156.2(C=O), $167.3(\mathrm{C}=\mathrm{O})$. MS (EI): $\mathrm{m} / \mathrm{z}(\%)=231.02$ Figures $2(\mathrm{a}), 2(\mathrm{~b}), 2(\mathrm{c})$, and $2(\mathrm{~d})$ represent the FT-IR, ${ }^{13} \mathrm{C},{ }^{1} \mathrm{H}$, and LC-MS of CFC respectively.

2.3. Synthesis of BFC. The mixture of CFC ( $0.0130 \mathrm{~mol}, 3 \mathrm{~g})$, benzhydryl piperazine $(0.0130 \mathrm{~mol}, 1.1363 \mathrm{~g})$, and formaldehyde $(0.01956 \mathrm{~mol}, 0.587 \mathrm{~g})$ were dissolved in ethanol.The reaction mixture was refluxed for $48 \mathrm{hrs}$ at $90^{\circ} \mathrm{C}$. The white solid obtained was filtered, washed with cold ethanol, and followed by petroleum ether. The resulting mass is dried and recrystallized from ethanol [4]. The BFC was characterized by spectral techniques like FT-IR, NMR, and LC-MS. Figure 3 represents the synthesis of $\mathrm{BFC}$.

2.4. Characterization of BFC. Yield 90\%, white solid, m.p.190-198 ${ }^{\circ}$ C., IR (KBr, vmax cm ${ }^{-1}$; $3265(\mathrm{NH}), 3058,3029$ (CH, Ar), 2942, 2808, 2757, 2698 (CH, Aliph), 1663 (C=O), 1591 (NH, bend), 1534, 1472 (C=C), 1335 (C-N, amide), 1188 (C-O, furan) 1138 (C-O), 1027 (C-N, Amine), 841 (CH, Ar, oop). ${ }^{1} \mathrm{H}$ NMR (300 MHz, $\mathrm{CDCl}_{3}$ ) d(ppm): $2.46(4 \mathrm{H}), 2.71$ $(4 \mathrm{H}), 4.24$ (s, $1 \mathrm{H}), 4.35$ (d, 2H, J=6 HZ), 6.59-6.63(m, 2H), 7.15-7.20 (m, 2H), 7.24-7.31 (m, 5H), 7.43(d, 4H, J=8.4 HZ), 7.55-7.56(m, 1H), 7.77 (d,2H, J=8.7 HZ), 7.85 (d, 2H, J=8.7 $\mathrm{HZ}), 8.23$ (s, 1H). ${ }^{13} \mathrm{C}$ NMR $\left(300 \mathrm{MHz}, \mathrm{CDCl}_{3}\right) \mathrm{d}(\mathrm{ppm})$ : $\delta$ MS (EI): $\mathrm{m} / \mathrm{z}(\%)=494.44$. Figures $4(\mathrm{a}), 4(\mathrm{~b}), 4(\mathrm{c})$, and 4(d) represent the FT-IR, ${ }^{13} \mathrm{C},{ }^{1} \mathrm{H}$, and LC-MS of CFC, respectively.

2.5. Medium. The standard solution of $1 \mathrm{M}$ hydrochloric acid was prepared using double distilled water. The concentration of the inhibitor BFC ranges from $0.20 \mathrm{mM}$ to $1.61 \mathrm{mM}$ in $1 \mathrm{M}$ hydrochloric acid. All the solutions were prepared in double distilled water.

2.6. Brass Sample. The chemical composition of working electrode, brass electrode [Cu (60.66\%), Zn (36.58\%), Sn $(1.02 \%)$, and $\mathrm{Fe}(1.74 \%)$ was used in rectangular form having dimension of $3.0 \mathrm{~cm}$ length and width $0.2 \mathrm{~cm}$ thickness with an exposed area of $7.6 \mathrm{~cm}^{2}$ for weight loss method. The specimen was mechanically ground with $320,400,600$, 800,1000 , and 1200 emery paper, washed in acetone and bidistilled water, then dried, and placed in a cell.

2.7. NMR Analysis. NMR and ${ }^{13} \mathrm{C}$ NMR spectrum of the Mannich bases BFC were recorded on a Bruker AC $300 \mathrm{~F} \mathrm{(300}$ and $400 \mathrm{MHz}$ ) NMR spectrometer using $\mathrm{CDCl} 3$, DMSO as solvents, and TMS as an internal standard.

2.8. Weight Loss Measurements. Weight loss experiments were carried out according to the method described previously [5]. Weight loss measurements were performed by immersing the brass coupons in $100 \mathrm{ml}$ of $1 \mathrm{M} \mathrm{HCl}$ solution 


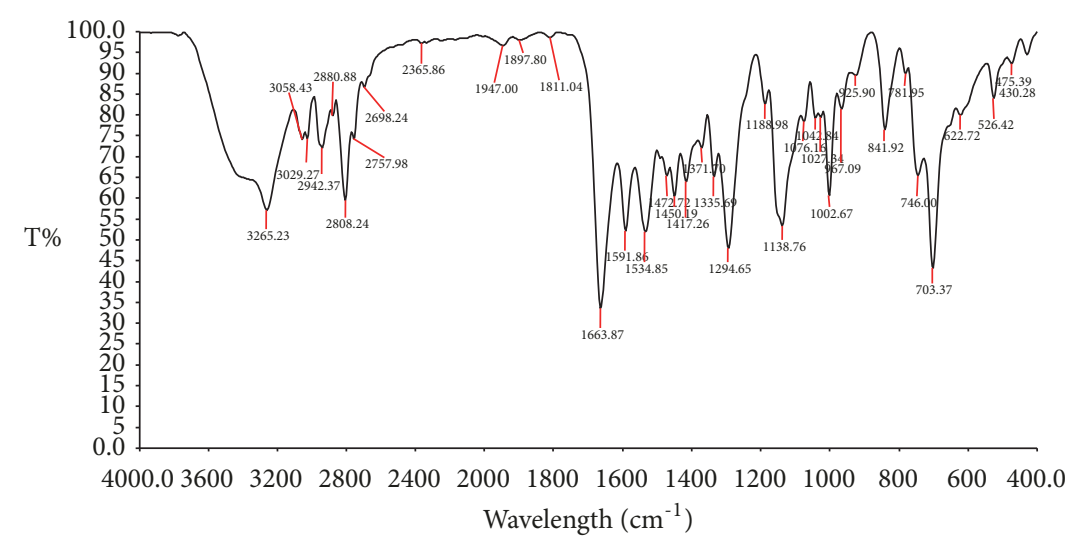

(a) FT-IR spectrum of BFC

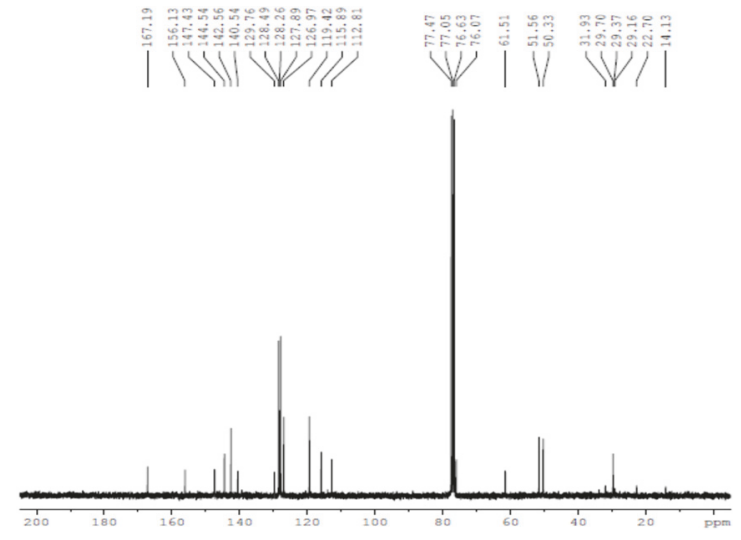

(b) ${ }^{13} \mathrm{C}$ spectrum of $\mathrm{BFC}$

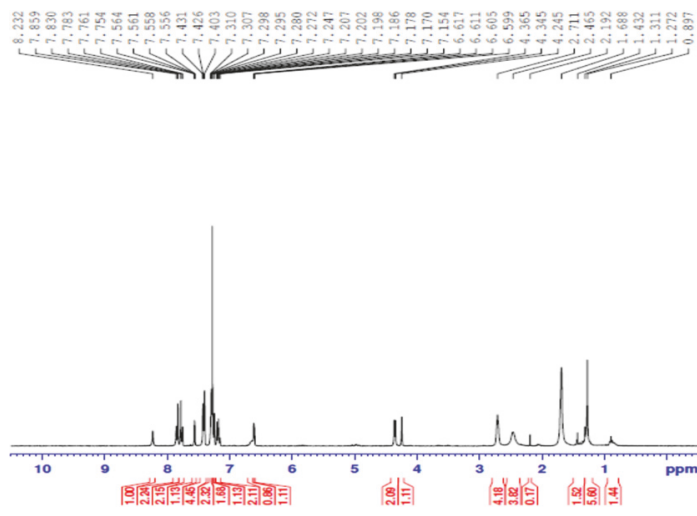

(c) ${ }^{1} \mathrm{H}$ spectrum of $\mathrm{BFC}$

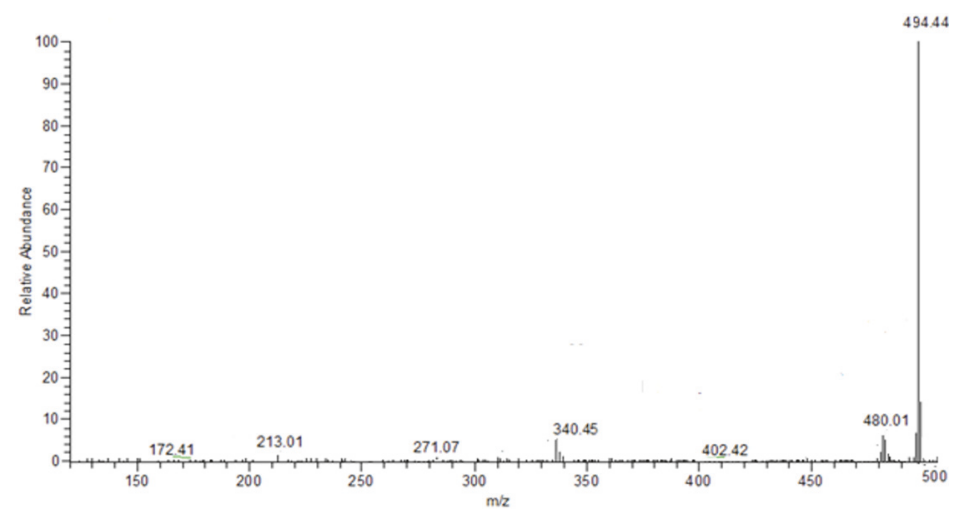

(d) LC-MS spectrum of BFC

Figure 4

with and without various amounts of inhibitor for 2 hours by varying the temperatures range from $30^{\circ} \mathrm{C}$ to $60^{\circ} \mathrm{C}$. After the elapsed time, the specimens were taken out, washed, dried, and weighed accurately. Triplicate test was performed for both blank and inhibitor and the average values were reported with standard deviation. The inhibition efficiency (IE) and surface coverage $(\theta)$ was determined by the following:

$$
\mathrm{I} . \mathrm{E}\left(\text { or) } \eta \%=\frac{\mathrm{W}_{0}-\mathrm{W}_{1}}{\mathrm{~W}_{0}} \times 100\right.
$$

$$
\theta=\frac{\mathrm{W}_{0}-\mathrm{W}_{1}}{\mathrm{~W}_{0}}
$$

where $\mathrm{W}_{1}$ and $\mathrm{W}_{0}$ are the weight loss values in the presence and absence of inhibitor.

2.9. Electrochemical Measurement. A three-electrode system consisting of brass coupons of $1.0 \mathrm{~cm}^{2}$ area exposed as working electrode (WE), platinum sheet as a counterelectrode (CE), and saturated calomel electrode (SCE) as a reference electrode was used for electrochemical measurements. The 
entire test was performed in atmospheric condition without stirring. Experiments were carried out in Electrochemical Workstation Model $608 \mathrm{D} / \mathrm{E}$ Series in $1 \mathrm{M} \mathrm{HCl}$ in the presence and absence of inhibitor. Prior to the electrochemical measurements, a stabilization period of 30 minutes was allowed, which is enough to attain stable $\mathrm{E}_{\text {corr }}$ value. Potentiodynamic polarization measurement was performed with the potential range of $\pm 200 \mathrm{mV}$ and the scan rate is $1.0 \mathrm{mV} \mathrm{s}^{-1}$. The inhibition efficiency (IE) and corrosion rate (CR) were calculated by using the following:

$$
\begin{aligned}
\mathrm{I} . \mathrm{E}(\text { or }) \eta \% & =\left[1-\left(\frac{\mathrm{i}_{\text {corr }}^{\prime}}{\mathrm{i}_{\text {corr }}}\right)\right] \times 100 \\
\mathrm{CR}(\mathrm{mmpy}) & =\frac{3270 \times \mathrm{M} \times \mathrm{i}_{\text {corr }}}{\rho \times \mathrm{Z}}
\end{aligned}
$$

where $i_{\text {corr }}^{\prime}$ and $i_{\text {corr }}$ are the corrosion current density of brass in the absence and presence of BFC. $M$ is atomic mass of metal, $\rho$ is density of corroding metal, and $\mathrm{Z}$ is number of electrons transferred per metal atom $(Z=2)[6]$.

After polarization measurements electrochemical impedance was carried out by varying the frequency from $100 \mathrm{MHz}$ to $100 \mathrm{KHz}$ [7]. The following equation is used to calculate inhibition efficiency $(\eta \%)$ and double layer capacitance $(\mathrm{Cdl})$ of BFC was calculated by

$$
\begin{aligned}
(\eta \%) & =\frac{\mathrm{R}_{c t 1}^{\mathrm{i}}-\mathrm{R}_{\mathrm{ct} 1}^{0}}{\mathrm{R}_{\mathrm{ct} 1}^{\mathrm{i}}} \\
\mathrm{Cdl} & =\frac{1}{2 \times 3.14 \times \mathrm{f}_{\max } \times \mathrm{Rct}}
\end{aligned}
$$

where $\mathrm{R}_{\text {ct } 1}^{0}$ and $\mathrm{R}_{\text {ct } 1}^{\mathrm{i}}$ are charge transfer resistance in the absence and presence of BFC, $\mathrm{f}_{\max }$ is the frequency, and Rct are the charge transfer resistance.

2.10. DFT Study. Quantum chemical calculations were performed using DFT method, and the structural parameters were geometrically optimized using functional hybrid RB3LYP with electron basis set 6-311G (d,p) for the atoms. All the calculations were performed with Gaussian 09. The quantum chemical parameters like $\mathrm{E}_{\mathrm{HOMO}}, \mathrm{E}_{\mathrm{LUMO}}$, energy gap $\left(\Delta \mathrm{E}=\mathrm{E}_{\mathrm{LUMO}}-\mathrm{E}_{\mathrm{HOMO}}\right)$, dipole moment $(\mu)$, absolute electronegativity $(\chi)$, global hardness $(\eta)$, global softness $(\sigma)$, and Mulliken charge were calculated.

\section{Results and Discussion}

3.1. Weight Loss Method. Table 1 indicates the effect of concentration of BFC on the corrosion of brass in $1 \mathrm{M} \mathrm{HCl}$. From the table the inhibition efficiency (IE) of BFC increases with an increase in the concentration of inhibitor and temperature [8]. The maximum inhibition efficiency obtained by this method was found to be $77.37 \%$ at a concentration of $1.41 \mathrm{mM}$ and further increase in the concentration and temperature of inhibitor (1.61 to $2.01 \mathrm{mM}, 60^{\circ} \mathrm{C}$ ) did not cause any appreciable change in the efficiency of BFC. This is due to the surface blocking effect of inhibitor on the metal by adsorption and film formation mechanism and also due to the presence of protonated nitrogen and the oxygen atom of BFC. The presence of nitrogen and oxygen atom present in BFC absorbs quickly on the metal surface with formation of an insoluble stable film; this makes the inhibitor more effective.

3.2. Tafel Polarization Measurements. Figures 5(a), 5(b), 5(c), and $5(\mathrm{~d})$ indicate the potentiodynamic polarization curves for the brass electrode in $1 \mathrm{M} \mathrm{HCl}$ solution with and without different concentrations of $\mathrm{BFC}$ at $60^{\circ} \mathrm{C}, 50^{\circ} \mathrm{C}, 40^{\circ} \mathrm{C}$, and $30^{\circ} \mathrm{C}$. It was clear that the current density decreases with the presence of BFC which indicates that inhibitor is adsorbed on the surface of metal. The values of corrosion potential $\left(\mathrm{E}_{\mathrm{corr}}\right)$ and corrosion current density $\left(\mathrm{i}_{\text {corr }}\right)$ are obtained by Tafel extrapolation method, anodic $\left(b_{a}\right)$ and cathodic $\left(b_{c}\right)$ These polarization curves indicate that there is a clear reduction of both anodic and cathodic currents in the presence of BFC compared with Blank solution.

The rate of corrosion for brass decreases as the concentration of BFC increases with respect to temperature. The presence of inhibitor decreases the rate of corrosion and $\mathrm{i}_{\text {corr }}$ prominently with an increase in the concentration of inhibitor related to a shift of corrosion potential $\left(\mathrm{E}_{\mathrm{corr}}\right)$ to more positive [9-11].

Further, the inhibition efficiency of BFC increases with an increase in concentration and temperature. It is due to physisorption of BFC molecule adsorbed at low temperature on brass surface, which is altered to chemisorptions at higher temperature. The maximum inhibition efficiency of BFC was found to be $86.79 \%$ in $1.41 \mathrm{mM}$ at $60^{\circ} \mathrm{C}$.

The corrosion kinetic parameters like corrosion potential $\left(\mathrm{E}_{\text {corr }}\right)$, corrosion current density $\left(\mathrm{i}_{\text {corr }}\right)$, and anodic $\left(\mathrm{b}_{\mathrm{a}}\right)$ and cathodic $\left(b_{c}\right)$ slopes in the presence and absence of inhibitor obtained from polarization curves were summarized in Table 2 . The corrosion current density $\left(\mathrm{i}_{\text {corr }}\right)$ is more compared with the inhibitor, because in $\mathrm{HCl}$ there is no inhibitor to cover brass surface. Hence dissolution of metal occurs on the surface of brass. The presence of inhibitor minimizes the acid attack due to the formation of compact and coherent layer on the surface of copper. The addition of inhibitor manifests the shift $\mathrm{E}_{\text {corr }}$ to a positive direction, which suppresses hydrogen evolution and metal dissolution reaction [12].

Many researchers discussed about the corrosion potential of inhibitor, if the potential shift exceeds with $\pm 85 \mathrm{mV}$ with respect to the potential of uninhibited solution, the inhibitor acts as either anodic or cathodic type, in addition to that $\mathrm{E}_{\text {corr }}$ vary within $\pm 50 \mathrm{mV}$, and then the inhibitor is mixed type inhibitor. In this present study, BFC acts as a mixed type inhibitor and undergoes both cathodic reaction (hydrogen evolution) and anodic reaction (metal dissolution) [13]. There was no definite trend observed for cathodic Tafel slope and anodic Tafel slope indicates that BFC was first adsorbed on the surface and impeded by merely blocking the reaction sites of the metal without affecting the reaction mechanism $[14,15]$. The result obtained from polarization technique was in good agreement with conventional weight loss method.

3.3. Electrochemical Impedance Spectroscopy. Nyquist plot of brass in $1 \mathrm{M} \mathrm{HCl}$ solution in the absence and presence of 
TABLE 1: Weight loss measurements of brass in $\mathrm{IM} \mathrm{HCl}$ with $\mathrm{BFC}$ from $30^{\circ} \mathrm{C}$ to $60^{\circ} \mathrm{C}$.

\begin{tabular}{|c|c|c|c|c|c|}
\hline S.No. & Temp. $\left({ }^{\circ} \mathrm{C}\right)$ & Con. of inhibitor (mM) & Corrosion rate (mmpy) & Surface coverage $(\theta)$ & Inhibition efficiency (I.E)\% \\
\hline \multirow[t]{8}{*}{1} & $30^{\circ} \mathrm{C}$ & Blank & 35.781 & - & - \\
\hline & & 0.20 & 15.742 & 0.4278 & 42.78 \\
\hline & & 0.40 & 13.552 & 0.4566 & 45.66 \\
\hline & & 0.60 & 9.840 & 0.4610 & 46.10 \\
\hline & & 0.80 & 7.174 & 0.5052 & 50.52 \\
\hline & & 1.01 & 6.711 & 0.5676 & 56.76 \\
\hline & & 1.21 & 5.061 & 0.6018 & 60.18 \\
\hline & & 1.41 & 4.770 & 0.6149 & 61.49 \\
\hline \multirow[t]{8}{*}{2} & $40^{\circ} \mathrm{C}$ & Blank & 65.517 & - & - \\
\hline & & 0.20 & 18.731 & 0.4681 & 46.81 \\
\hline & & 0.40 & 16.874 & 0.4707 & 47.07 \\
\hline & & 0.60 & 15.364 & 0.4935 & 49.35 \\
\hline & & 0.80 & 12.809 & 0.5309 & 53.09 \\
\hline & & 1.01 & 9.781 & 0.5866 & 58.66 \\
\hline & & 1.21 & 6.846 & 0.6211 & 62.11 \\
\hline & & 1.41 & 5.224 & 0.6324 & 63.24 \\
\hline \multirow[t]{8}{*}{3} & $50^{\circ} \mathrm{C}$ & Blank & 98.182 & - & - \\
\hline & & 0.20 & 50.175 & 0.4920 & 49.20 \\
\hline & & 0.40 & 48.011 & 0.5013 & 50.13 \\
\hline & & 0.60 & 43.521 & 0.5367 & 53.67 \\
\hline & & 0.80 & 37.540 & 0.5671 & 56.71 \\
\hline & & 1.01 & 35.839 & 0.5930 & 59.30 \\
\hline & & 1.21 & 29.743 & 0.6388 & 63.88 \\
\hline & & 1.41 & 22.585 & 0.6500 & 65.00 \\
\hline \multirow[t]{8}{*}{4} & $60^{\circ} \mathrm{C}$ & Blank & 468.822 & - & - \\
\hline & & 0.20 & 62.743 & 0.5486 & 54.86 \\
\hline & & 0.40 & 58.770 & 0.5637 & 56.37 \\
\hline & & 0.60 & 50.982 & 0.6053 & 60.53 \\
\hline & & 0.80 & 46.418 & 0.6652 & 66.50 \\
\hline & & 1.01 & 44.730 & 0.7192 & 71.92 \\
\hline & & 1.21 & 36.641 & 0.7632 & 76.32 \\
\hline & & 1.41 & 30.150 & 0.7737 & 77.37 \\
\hline
\end{tabular}

different concentration of $\mathrm{BFC}$ at $60^{\circ} \mathrm{C}, 50^{\circ} \mathrm{C}, 40^{\circ} \mathrm{C}$, and $30^{\circ} \mathrm{C}$ was shown in Figures 6(a), 6(b), 6(c), and 6(d). The Nyquist plot consists of a large capacitive loop at high frequency followed by a small inductive loop at low frequency value. The high frequency capacitive loop is due to charge transfer resistance of the corrosion process and electrical double layer [16]. At lower frequency the loop is attributed to the relaxation process of the adsorbed intermediates by controlling the anodic process [17]. The impedance spectra of BFC were deviated from perfect semicircle due to frequency dispersion effect as a result of roughness and in-homogeneity on the metal surface $[18,19]$. Furthermore, the diameter of the capacitive loop in presence of $\mathrm{BFC}$ is higher than in $\mathrm{HCl}$ and its magnitude is a function of the inhibitor concentration.
The values of charge transfer resistance (Rct) and double layer capacitance (Cdl) obtained from the Nyquist plot and the calculated inhibition efficiency value were reported in Table 3. From the table it is obvious that the value of Cdl decreases as the concentration of inhibitor increases. The decrease in Cdl value is due to increase in local dielectric constant and increase in electrical double layer, suggesting that the inhibitor undergoes adsorption by forming a protective layer on the metal surface with dissolution $[20,21]$. The maximum inhibition efficiency of BFC was found to be $91.07 \%$ at $60^{\circ} \mathrm{C}$ for $1.41 \mathrm{Mm}$ of BFC.

To fit the experimental impedance data of brass a simple Randle's equivalent circuit was shown in Figure 6(e) in the absence and presence of BFC. In Figure 6(e) (Rs) is solution 
TABLE 2: Tafel polarization parameters for brass in $1 \mathrm{M} \mathrm{HCl}$ with $\mathrm{BFC}$ from $30^{\circ} \mathrm{C}$ to $60^{\circ} \mathrm{C}$.

\begin{tabular}{|c|c|c|c|c|c|c|c|}
\hline S.No. & Temp. $\left({ }^{\circ} \mathrm{C}\right)$ & Conc. of inhibitor (mM) & $\mathrm{E}_{\text {corr }}(\mathrm{V} / \mathrm{SCE})$ & $-b_{a}\left(m V \operatorname{dec}^{-1}\right)$ & $-b_{c}\left(m V \operatorname{dec}^{-1}\right)$ & $\mathrm{i}_{\text {corr }}\left(\mathrm{mA} \mathrm{cm}^{-2}\right)$ & IE\% \\
\hline \multirow[t]{8}{*}{1} & $30^{\circ} \mathrm{C}$ & Blank & -0.483 & 6.85 & 6.78 & 3.846 & - \\
\hline & & 0.20 & -0.516 & 11.63 & 5.94 & 1.882 & 51.06 \\
\hline & & 0.40 & -0.548 & 10.54 & 5.70 & 1.723 & 55.20 \\
\hline & & 0.60 & -0.549 & 11.77 & 4.88 & 1.570 & 59.17 \\
\hline & & 0.80 & -0.546 & 11.10 & 4.17 & 1.401 & 63.57 \\
\hline & & 1.01 & -0.550 & 11.62 & 6.72 & 1.398 & 63.65 \\
\hline & & 1.21 & -0.566 & 11.82 & 6.87 & 1.354 & 64.79 \\
\hline & & 1.41 & -0.599 & 12.68 & 6.11 & 1.136 & 70.46 \\
\hline \multirow[t]{8}{*}{2} & $40^{\circ} \mathrm{C}$ & Blank & -0.466 & 5.663 & 6.36 & 5.728 & - \\
\hline & & 0.20 & -0.468 & 6.631 & 6.77 & 2.457 & 57.10 \\
\hline & & 0.40 & -0.470 & 6.178 & 8.82 & 2.280 & 60.19 \\
\hline & & 0.60 & -0.466 & 8.817 & 8.70 & 2.161 & 62.27 \\
\hline & & 0.80 & -0.474 & 8.875 & 8.97 & 1.986 & 65.32 \\
\hline & & 1.01 & -0.478 & 9.957 & 8.18 & 1.804 & 68.50 \\
\hline & & 1.21 & -0.482 & 13.25 & 8.50 & 1.629 & 71.56 \\
\hline & & 1.41 & -0.493 & 11.50 & 6.90 & 1.472 & 74.30 \\
\hline \multirow[t]{8}{*}{3} & $50^{\circ} \mathrm{C}$ & Blank & -0.433 & 6.307 & 6.09 & 8.532 & - \\
\hline & & 0.20 & -0.446 & 6.128 & 8.51 & 3.428 & 59.82 \\
\hline & & 0.40 & -0.451 & 8.695 & 7.62 & 3.276 & 61.60 \\
\hline & & 0.60 & -0.459 & 13.30 & 7.84 & 3.174 & 62.79 \\
\hline & & 0.80 & -0.466 & 13.81 & 6.81 & 2.862 & 66.45 \\
\hline & & 1.01 & -0.472 & $11 . .68$ & 6.22 & 2.650 & 68.94 \\
\hline & & 1.21 & -0.473 & 8.105 & 8.90 & 2.266 & 73.44 \\
\hline & & 1.41 & -0.461 & 11.73 & 6.78 & 1.951 & 77.13 \\
\hline \multirow[t]{8}{*}{4} & $60^{\circ} \mathrm{C}$ & Blank & -0.423 & 5.681 & 6.36 & 9.578 & - \\
\hline & & 0.20 & -0.436 & 7.897 & 7.45 & 3.773 & 60.60 \\
\hline & & 0.40 & -0.437 & 11.32 & 6.95 & 3.562 & 62.81 \\
\hline & & 0.60 & -0.442 & 12.92 & 7.98 & 3.118 & 67.44 \\
\hline & & 0.80 & -0.448 & 10.91 & 7.44 & 3.046 & 68.19 \\
\hline & & 1.01 & -0.451 & 10.17 & 6.76 & 2.852 & 70.22 \\
\hline & & 1.21 & -0.457 & 10.33 & 9.06 & 2.312 & 75.86 \\
\hline & & 1.41 & -0.478 & 13.42 & 7.63 & 1.268 & 86.79 \\
\hline
\end{tabular}

resistance, (Rct1) is charge transfer resistance with porous structure on brass surface, (Rct2) is charge transfer resistance with adsorption of inhibitor on brass surface and it acts as a resistor, $(\mathrm{W})$ is Warburg impedance, $(\mathrm{CPE} 1)$ is first constant phase element, and (CPE2) is second constant phase element. In this Randle's equivalent circuit, (CPE) is used instead of a pure capacitor owing the frequency dispersion of semicircle.

The rough solid electrode, a constant phase element and $\left(\mathrm{Z}_{\mathrm{CPE}}\right)$ were described by the following:

$$
\left(\mathrm{Z}_{\mathrm{CPE}}\right)=\mathrm{Y}_{0}^{-1}(\mathrm{i} \omega)^{-\mathrm{n}}
$$

where $\mathrm{Y}_{0}$ is a proportionality factor, $\omega$ is the angular frequency, and $\mathrm{n}$ is the CPE exponent whose value lies between 0 and 1 and it is used as a gauge of in-homogeneity or roughness on the brass surface. The n-values of first constant phase element (CPE 1) lie between 0.47 to 0.76 representing double layer capacitance. Addition of inhibitor increases the $n$ value thereby decreasing the $\mathrm{CPE}$. The second constant phase element (CPE 2) is nearly Warburg impedance [22].

3.4. Cyclic Voltammetry Measurements. The mechanism of copper corrosion in $\mathrm{HCl}$ solution has been studied by many researchers and the main reaction that can take place in the acidic medium is given as follows $[23,24]$ :

$$
\begin{aligned}
& \mathrm{Cu}_{(\mathrm{s})}+\mathrm{Cl}^{-}{ }_{(\mathrm{aq})} \rightleftharpoons \mathrm{CuCl}_{(\mathrm{aq})}+\mathrm{e} \\
& \mathrm{CuCl}_{(\mathrm{aq})}+\mathrm{Cl}^{-}{ }_{(\mathrm{aq})} \rightleftharpoons \mathrm{CuCl}_{2}^{-}{ }_{(\mathrm{aq})} \\
& \mathrm{CuCl}_{2}^{-{ }_{(\mathrm{aq})}} \rightleftharpoons \mathrm{Cu}_{(\mathrm{aq})}^{2+}+2 \mathrm{Cl}^{-}{ }_{(\mathrm{aq})}+\mathrm{e}^{-} \\
& 2 \mathrm{CuCl}_{2}^{-}{ }_{(\mathrm{aq})}+2 \mathrm{OH}_{(\mathrm{l})}^{-} \\
& \longrightarrow \mathrm{Cu}_{2} \mathrm{O}_{(\mathrm{s})}+4 \mathrm{Cl}_{(\mathrm{aq})}^{-}+\mathrm{H}_{2} \mathrm{O}_{(\mathrm{aq})}
\end{aligned}
$$




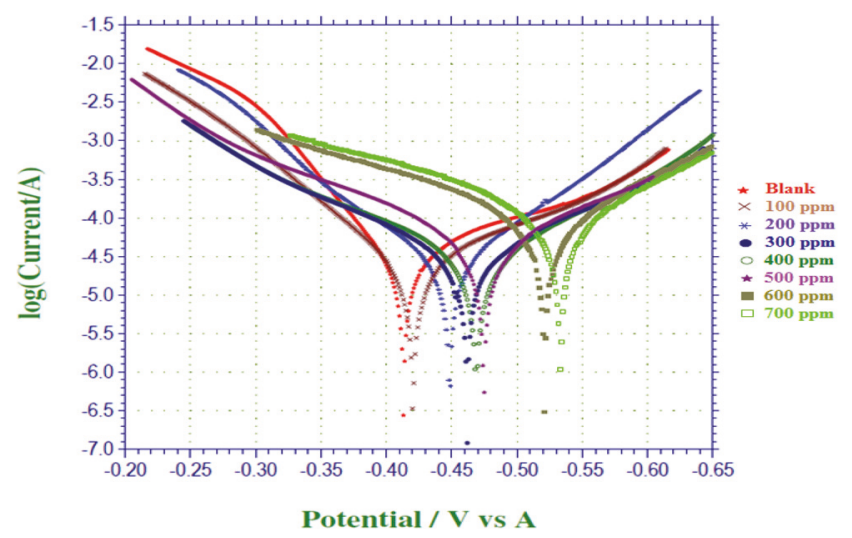

(a) Potentiodynamic polarization curves of $\mathrm{BFC}$ for brass in $1 \mathrm{M} \mathrm{HCl}$ at $60^{\circ} \mathrm{C}$

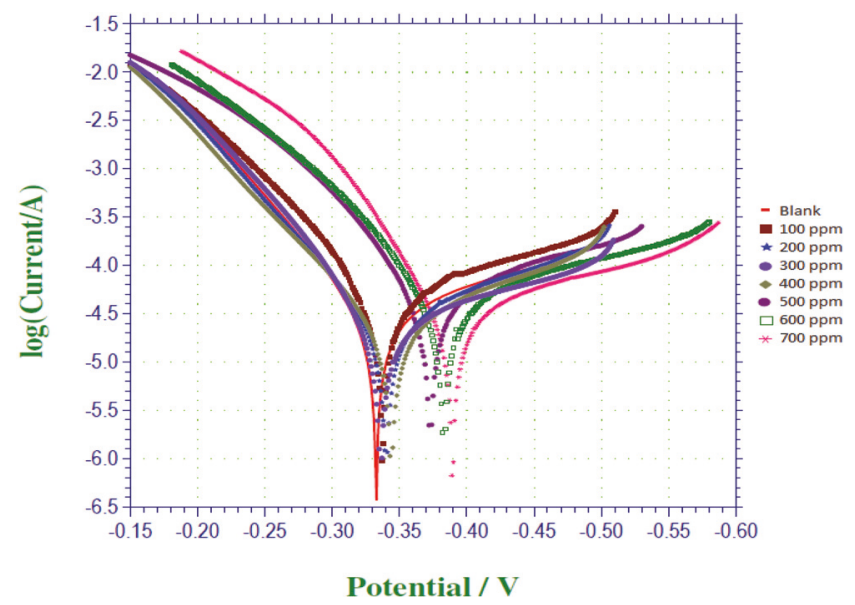

(c) Potentiodynamic polarization curves of $\mathrm{BFC}$ for brass in $1 \mathrm{M} \mathrm{HCl}$ at $40^{\circ} \mathrm{C}$

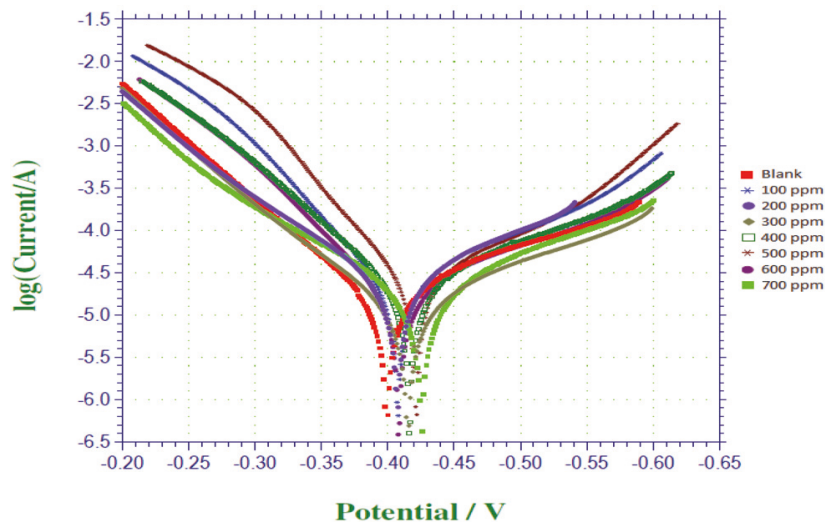

(b) Potentiodynamic polarization curves of BFC for brass in $1 \mathrm{M} \mathrm{HCl}$ at $50^{\circ} \mathrm{C}$

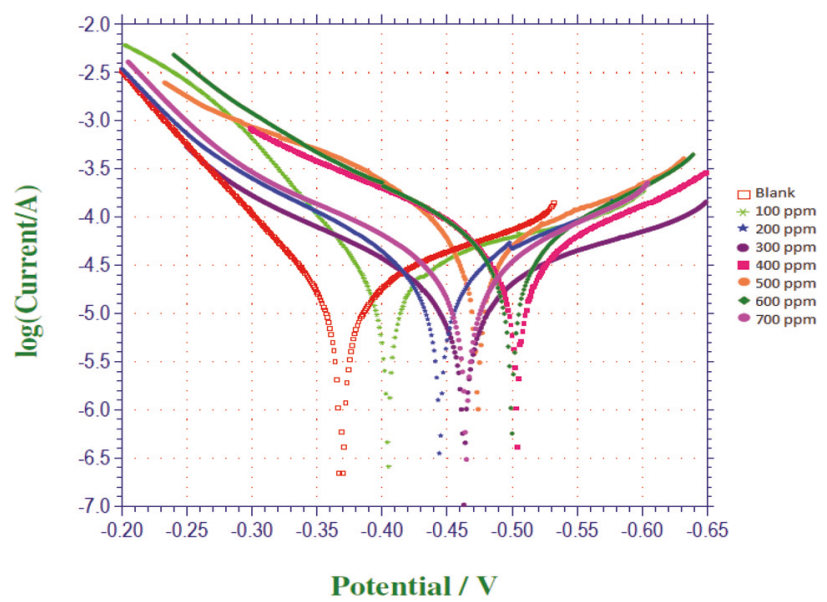

(d) Potentiodynamic polarization curves of $\mathrm{BFC}$ for brass in $1 \mathrm{M} \mathrm{HCl}$ at $30^{\circ} \mathrm{C}$

Figure 5

$$
\begin{gathered}
\mathrm{Cu}_{2} \mathrm{O}_{(\mathrm{s})}+\frac{1}{2} \mathrm{O}_{2(\mathrm{aq})}+\mathrm{Cl}_{(\mathrm{aq})}^{-}+2 \mathrm{H}_{2} \mathrm{O}_{(\mathrm{aq})} \\
\longrightarrow \mathrm{Cu}_{2}(\mathrm{OH})_{3}+\mathrm{OH}^{-}
\end{gathered}
$$

In this mechanism, $\mathrm{CuCl}_{(\mathrm{aq})}$ is adsorbed on the surface of copper electrode. In acidic medium the presence of $\mathrm{CuCl}_{(\mathrm{aq})}$ layer is destroyed and the rate of corrosion is more. In presence of inhibitor the $\mathrm{CuCl}_{(\mathrm{aq})}$ layer adsorption is strong which is formed on the surface of copper acts as protective layer thereby preventing the oxidation of copper. The dissolution of $\mathrm{CuCl}_{2}{ }^{-}$(aq) takes place from $\mathrm{CuCl}_{(\mathrm{aq})}$ occurring according to (10). Further there is an opportunity of oxidation reaction (11) and (12).

The cyclic voltammogram for brass in $1 \mathrm{M} \mathrm{HCl}$ in the absence and presence of inhibitor was shown in Figures 7(a), $7(\mathrm{~b}), 7(\mathrm{c})$, and $7(\mathrm{~d})$ at $60^{\circ} \mathrm{C}, 50^{\circ} \mathrm{C}, 40^{\circ} \mathrm{C}$, and $30^{\circ} \mathrm{C}$. It was observed that bare brass shows an oxidation peaks at the forward scan of $0.289 \mathrm{~V}$ (SCE). The formation of oxidation peak is due to the $\mathrm{Cu}^{2+}$ or due to the formation of an insoluble $\mathrm{Cu}_{2} \mathrm{O}$ or due to hydroxychloride reactions from (9)-(12). In reverse sweep also there is a reduction peak occurring at $-0.468 \mathrm{~V}$ (SCE) which is due to the reduction of $\mathrm{Cu}^{2+}$ and insoluble $\mathrm{Cu}_{2} \mathrm{O}$ layer formed during the oxidation process.
The cyclic voltammogram as shown in Figures shows the effect of the addition of various concentrations of the inhibitor. It is interesting to note that two main changes have occurred with the addition of the inhibitor. First one exhibits only one peak for brass in both forward and reverse sweep at around $-0.12 \mathrm{~V}$ (SCE) for the forward scan and +0.214 for the reverse sweep. The reduction in the Volt is attributed to adsorption of the inhibitor on the brass surface. The second change is the reduction of the oxidation and reduction peak, which diminishes drastically with the addition of the inhibitor. This observation indicates that the inhibitor added to the solution is adsorbed on the brass surface effectively and reduces the oxidation of the copper in the brass.

By comparing the cyclic voltammogram of brass and BFC modified brass, the addition of inhibitor diminishes the oxidation and reduction peak drastically and there are shifts of peak potential from positive to negative direction, respectively. These observations reveal that the addition of inhibitor is adsorbed on the surface of brass effectively and reduces the oxidation of the copper in the brass.

The cyclic voltammogram of brass and various concentrations of the inhibitor was carried out at the voltage range of $-1.2 \mathrm{~V}$ to $1 \mathrm{~V}$ and scan rate was $0.05 \mathrm{~V}$. These range was fixed 


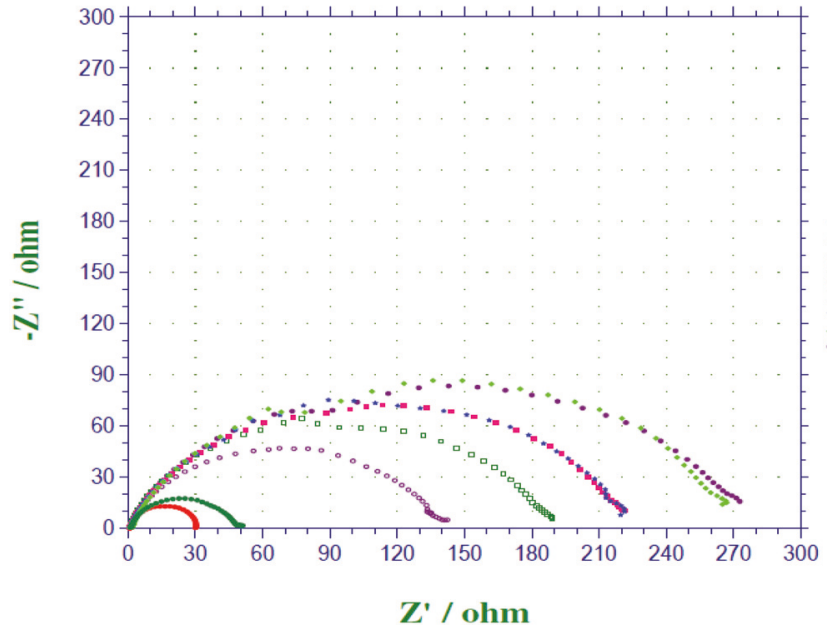

(a) $\mathrm{AC}$ impedance curves of $\mathrm{BFC}$ for brass in $1 \mathrm{M} \mathrm{HCl}$ at $60^{\circ} \mathrm{C}$

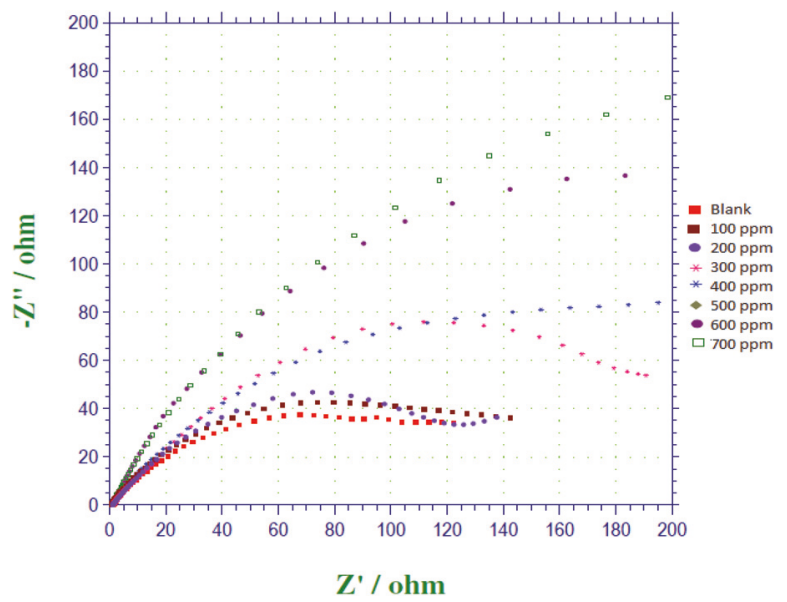

(c) AC impedance curves of $\mathrm{BFC}$ for brass in $1 \mathrm{M} \mathrm{HCl}$ at $40^{\circ} \mathrm{C}$

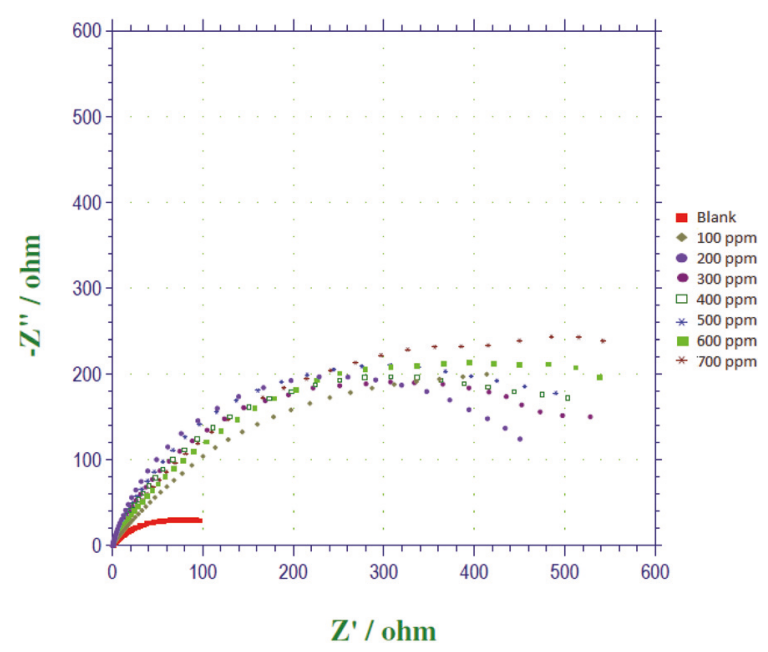

(b) $\mathrm{AC}$ impedance curves of $\mathrm{BFC}$ for brass in $1 \mathrm{M} \mathrm{HCl}$ at $50^{\circ} \mathrm{C}$

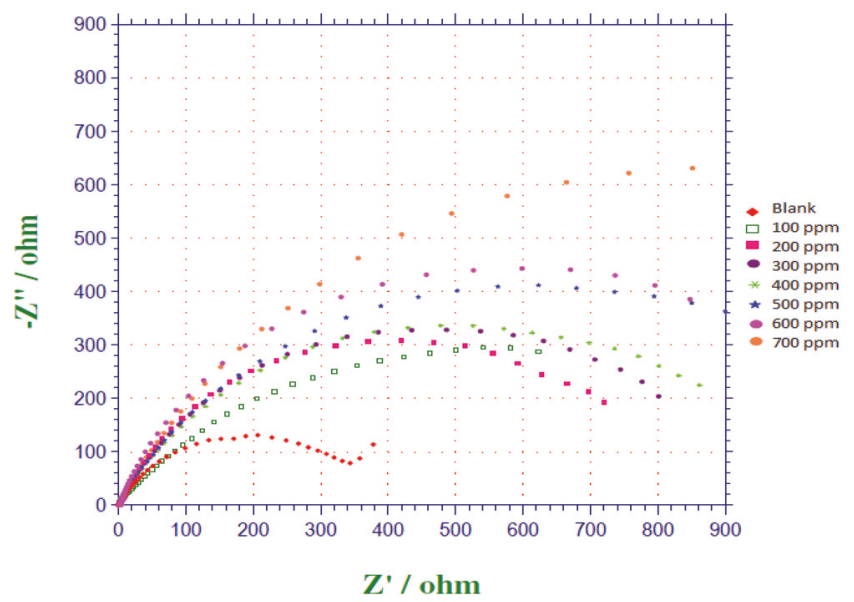

(d) $\mathrm{AC}$ impedance curves of $\mathrm{BFC}$ for brass in $1 \mathrm{M} \mathrm{HCl}$ at $30^{\circ} \mathrm{C}$

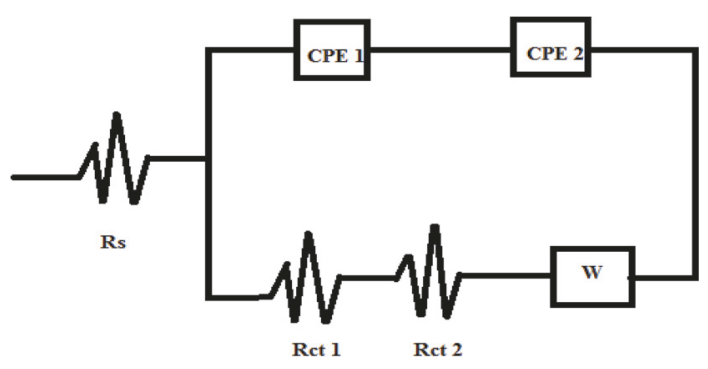

(e) Randle's Equivalent circuit used to fit the impedance spectra

Figure 6

to carry out the oxidation and reduction potential of $\mathrm{Zn}$ and copper ions in various oxidation state.

3.5. Dezincification Factor by AAS. Dezincification factor is used to measure the percentage of copper and zinc ion present in the $\mathrm{HCl}$ solution from weight loss method using atomic absorption spectroscopy (AAS) (Elico-India). Dezincification factor is calculated by the following equation where the concentration of zinc and copper is in ppm [25].

$$
\text { Dezincification factor }(\mathrm{Z})=\frac{(\mathrm{Zn} / \mathrm{Cu}) \text { solution }}{(\mathrm{Zn} / \mathrm{CU}) \text { Alloy }}
$$

Dezincification of $1 \mathrm{M} \mathrm{HCl}$ and the optimum concentration of the inhibitor (700ppm) were shown in Table 4. From the table it was observed that copper and zinc both are leached in the $\mathrm{HCl}$ solution. The ratio of copper to zinc ion present in the $\mathrm{HCl}$ solution was much lesser than in the alloy.

This is due to the diffusion of ion and it is mainly controlled by the dissolution of the alloy. Copper is less leached than zinc in $\mathrm{HCl}$ solution, because $\mathrm{E}_{(\mathrm{cu} 2+/ \mathrm{Cu})}^{\mathrm{O}}$ for copper $(+0.34 \mathrm{~V})$ has a positive value and $\mathrm{E}^{\mathrm{o}}{ }_{(\mathrm{Zn} 2+/ \mathrm{Zn})}$ for $\mathrm{Zn}$ is $(-0.76)$ negative. The diffusion of ion is very much related to the size of the ion; zinc (II) ion having an atomic radius 


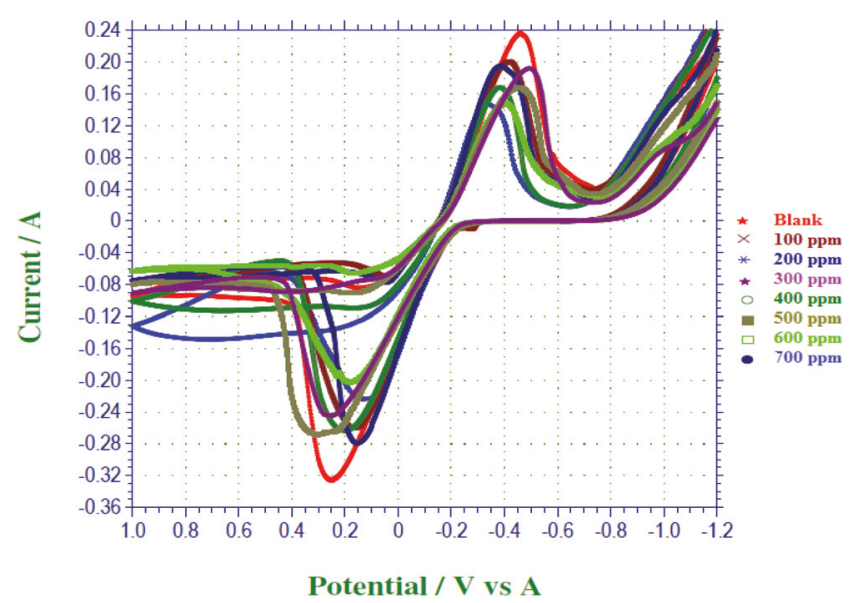

(a) $\mathrm{CV}$ for brass in $1 \mathrm{M} \mathrm{HCl}$ in the absence and presence $\mathrm{BFC}$ at $60^{\circ} \mathrm{C}$

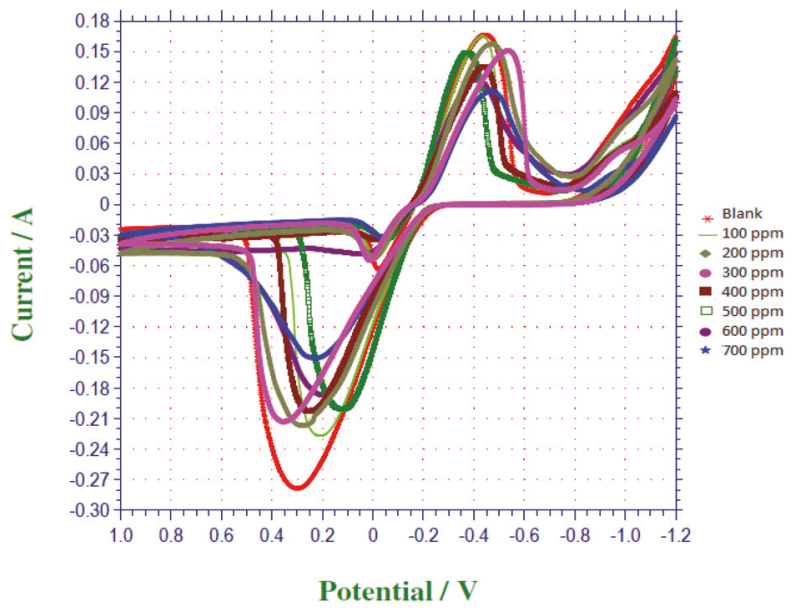

(c) $\mathrm{CV}$ for brass in $1 \mathrm{M} \mathrm{HCl}$ in the absence and presence $\mathrm{BFC}$ at $40^{\circ} \mathrm{C}$

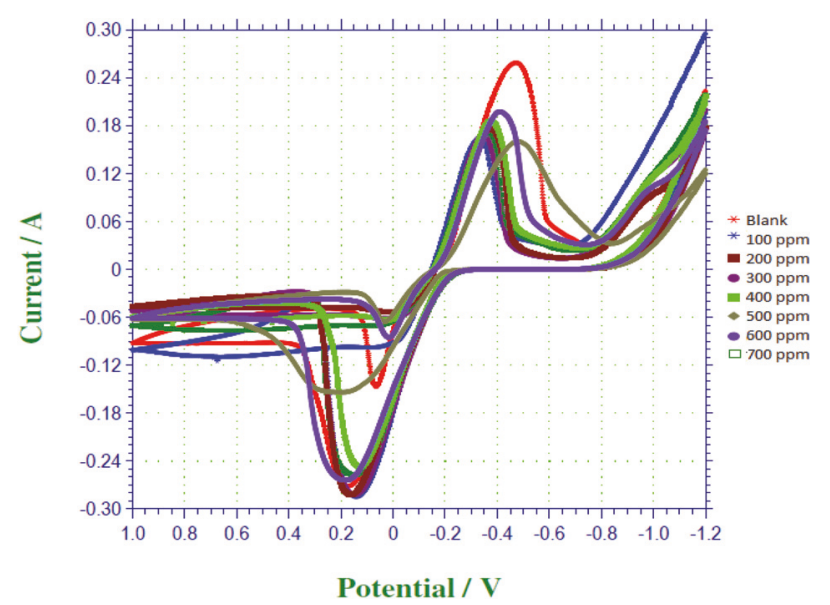

(b) $\mathrm{CV}$ for brass in $1 \mathrm{M} \mathrm{HCl}$ in the absence and presence $\mathrm{BFC}$ at $50^{\circ} \mathrm{C}$

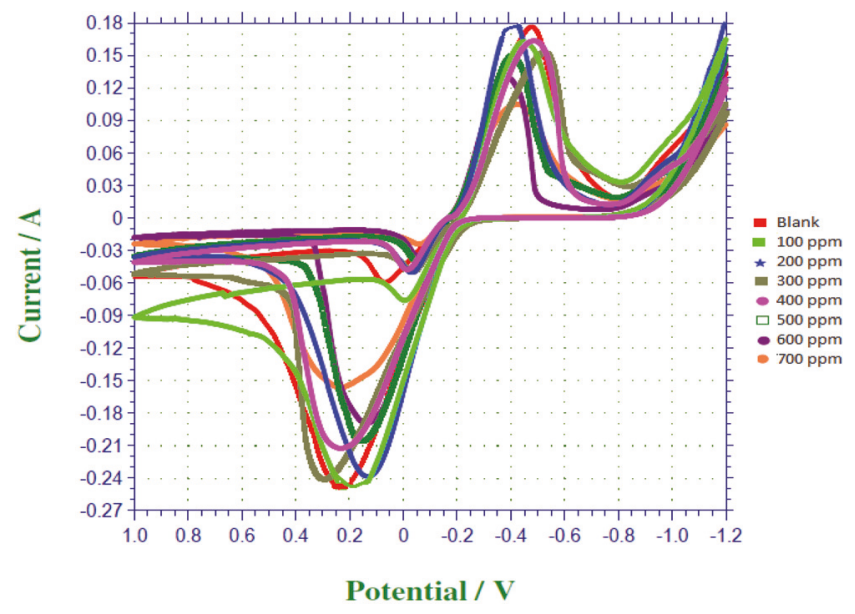

(d) $\mathrm{CV}$ for brass in $1 \mathrm{M} \mathrm{HCl}$ in the absence and presence $\mathrm{BFC}$ at $30^{\circ} \mathrm{C}$

Figure 7

of $0.074 \mathrm{~nm}$ diffuses faster than the copper (II) ion which has atomic radius of $0.096 \mathrm{~nm}$. The leaching of copper and zinc ion was minimized by the addition of the inhibitor. But the percentage of the zinc present in inhibitor was much higher than the copper. The dezincification factor of BFC is 34.22 compared with $1 \mathrm{M} \mathrm{HCl}$ which was 62.16 . This indicates that the dezincification factor is reduced by the addition of inhibitor by $27.94 \%$. Results reveal that BFC inhibits the dezincification of brass in $1 \mathrm{M} \mathrm{HCl}$ at optimum concentration efficiently [26].

3.6. Langmuir Adsorption Isotherm. The corrosion action of BFC was characterized by various adsorption isotherm like Langmuir, Freundlich, Temkin, Flory-Huggins, and ElAwady. All these adsorption isotherms follow a general expression as given in the following:

$$
\mathrm{f}(\theta, \mathrm{x}) \mathrm{e}^{(-2 \mathrm{a} \theta)}=\mathrm{KC}
$$

where $\mathrm{f}(\theta, \mathrm{x})$ is the configurational factor, $\theta$ is the surface coverage, $\mathrm{K}$ is the constant of the adsorption process and can be equated to equilibrium constant, $\mathrm{C}$ is the inhibitors concentration expressed in molarity, and a is the molecular interaction parameter. By careful examination of the $\mathrm{R}^{2}$ value of the various isotherm, Langmuir isotherm was found to fit well with the data of corrosion inhibition. Langmuir isotherm model for the adsorption of BFC on the Brass surface can be represented as follows [27]:

$$
\frac{\mathrm{C}}{\theta}=\frac{1}{\mathrm{~K}}+\mathrm{C}
$$

Plot of $\mathrm{C} / \theta$ versus $\mathrm{C}$ for various temperatures of $\mathrm{BFC}$ is shown in Figure 8 Table 5 shows the values of $R^{2}$, slope, $\Delta G$, and $\mathrm{K}_{\mathrm{ads}}$. The table implies that the slope of the line for the adsorption isotherm is greater than 1.12 at all temperatures which shows that each molecule of BFC occupies more than one site of adsorption in the brass metal. Higher adsorption capacity of BFC means there would be higher corrosion efficiency on the brass.

The inhibition of corrosion mechanism of the BFC on the surface of brass was monitored using the surface coverage. Tafel polarization was used for the measurement of the 
TABLE 3: AC impedance parameters for brass in $1 \mathrm{M} \mathrm{HCl}$ with $\mathrm{BFC}$ from $30^{\circ} \mathrm{C}$ to $60^{\circ} \mathrm{C}$.

\begin{tabular}{|c|c|c|c|c|c|}
\hline S.No. & Temp. $\left({ }^{\circ} \mathrm{C}\right)$ & Conc.of inhibitor (mM) & $\operatorname{Rct}\left(\mathrm{ohm} \mathrm{cm}{ }^{2}\right)$ & $\mathrm{Cdl}\left(\mathrm{ohm} \mu \mathrm{F} / \mathrm{cm}^{2}\right)$ & I.E \% \\
\hline \multirow[t]{8}{*}{1.} & $30^{\circ} \mathrm{C}$ & Blank & 28.9 & 298.0 & - \\
\hline & & 0.20 & 62.6 & 167.5 & 53.83 \\
\hline & & 0.40 & 68.7 & 155.0 & 57.93 \\
\hline & & 0.60 & 73.5 & 149.3 & 60.68 \\
\hline & & 0.80 & 79.4 & 141.7 & 63.60 \\
\hline & & 1.01 & 86.3 & 136.2 & 66.51 \\
\hline & & 1.21 & 94.1 & 135.4 & 69.28 \\
\hline & & 1.41 & 103.6 & 113.9 & 72.10 \\
\hline \multirow[t]{8}{*}{2.} & $40^{\circ} \mathrm{C}$ & Blank & 21.7 & 382.0 & - \\
\hline & & 0.20 & 51.8 & 268.7 & 58.10 \\
\hline & & 0.40 & 58.3 & 229.0 & 62.77 \\
\hline & & 0.60 & 66.5 & 215.0 & 67.36 \\
\hline & & 0.80 & 74.3 & 209.0 & 70.74 \\
\hline & & 1.01 & 78.9 & 195.7 & 72.49 \\
\hline & & 1.21 & 85.2 & 191.6 & 74.53 \\
\hline & & 1.41 & 89.5 & 177.0 & 75.78 \\
\hline \multirow[t]{8}{*}{3.} & $50^{\circ} \mathrm{C}$ & Blank & 10.67 & 975.0 & - \\
\hline & & 0.20 & 28.1 & 582.4 & 62.02 \\
\hline & & 0.40 & 30.5 & 570.0 & 65.01 \\
\hline & & 0.60 & 37.2 & 559.8 & 71.31 \\
\hline & & 0.80 & 40.9 & 533.0 & 73.91 \\
\hline & & 1.01 & 45.3 & 517.9 & 76.44 \\
\hline & & 1.21 & 47.6 & 507.5 & 77.58 \\
\hline & & 1.41 & 59.8 & 480.2 & 82.15 \\
\hline \multirow[t]{8}{*}{4.} & $60^{\circ} \mathrm{C}$ & Blank & 7.5 & 1126 & - \\
\hline & & 0.20 & 24.8 & 954.0 & 62.09 \\
\hline & & 0.40 & 27.9 & 922.8 & 63.74 \\
\hline & & 0.60 & 35.4 & 879.0 & 68.37 \\
\hline & & 0.80 & 39.7 & 823.0 & 71.73 \\
\hline & & 1.01 & 47.5 & 760.5 & 73.51 \\
\hline & & 1.21 & 56.3 & 731.0 & 80.57 \\
\hline & & 1.41 & 84.0 & 674.4 & 91.07 \\
\hline
\end{tabular}

TABLE 4: Solution analysis by AAS for brass in $1 \mathrm{M} \mathrm{HCl}$ with BFC.

\begin{tabular}{lccccc}
\hline \multirow{2}{*}{ Conc. of inhibitor $(\mathrm{ppm})$} & \multicolumn{2}{c}{ Solution Analysis } & Dezincification factor & \multicolumn{2}{c}{ Inhibition (\%) } \\
& $\mathrm{Cu}(\mathrm{ppm})$ & $\mathrm{Zn}(\mathrm{ppm})$ & $\mathrm{Cu}$ & $\mathrm{Zn}$ \\
\hline $1 \mathrm{M} \mathrm{HCl}$ & 0.1170 & 8.179 & 62.16 & - \\
\hline BFC $(700 \mathrm{ppm})$ & 0.0524 & 0.804 & 34.22 & 81.07 & 92.11 \\
\hline
\end{tabular}

TABLE 5: Equilibrium and statistical parameter for adsorption of MFC on Brass surface in $1 \mathrm{M} \mathrm{HCl}$.

\begin{tabular}{lllll}
\hline Temperature $(\mathrm{K})$ & $\mathrm{R}^{2}$ & $\mathrm{~K}_{\text {ads }}$ & slope & $\Delta \mathrm{G}$ \\
\hline 303 & 0.979 & 3276 & 1.452 & -30.5087 \\
\hline 313 & 0.984 & 3839 & 1.345 & \\
\hline 323 & 0.991 & 4735 & 1.294 & -31.931 \\
\hline 333 & 0.983 & 4135 & 1.124 & -33.514 \\
\hline
\end{tabular}




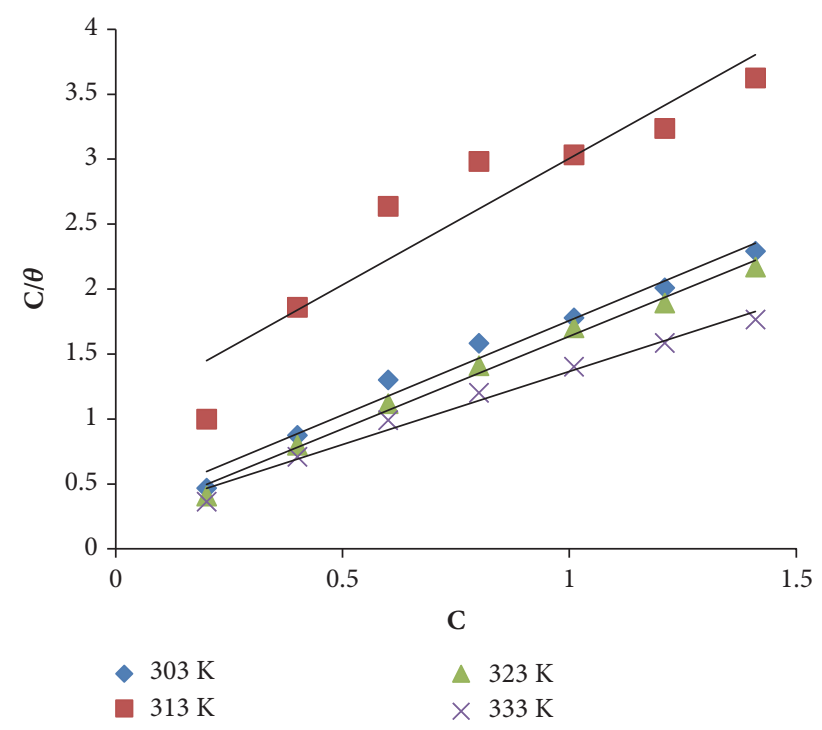

Figure 8: Plot of $\mathrm{C} / \theta$ versus $\mathrm{C}$ for various temperature with BFC.

surface coverage $\theta$ at different inhibitor concentration. Calculation of surface coverage $(\theta)$ calculation was given in the following formula:

$$
\begin{aligned}
\theta & =\frac{V \mathrm{o}-\mathrm{V}}{\mathrm{Vo}} \\
\Delta \mathrm{G}^{\mathrm{o}}{ }_{\mathrm{ads}} & =-\mathrm{RT}\left(\ln 55.5 \mathrm{~K}_{\mathrm{ads}}\right)
\end{aligned}
$$

where $\mathrm{Vo}$ is the corrosion rate without inhibitor and $\mathrm{V}$ is the corrosion rate with inhibitor. Various isotherms were tried with the value of $\theta$ and the best fit was found and as described earlier Langmuir isotherm showed the best fit.

$\Delta \mathrm{G}^{\mathrm{o}}$ ads was calculated using (17) and is give in Table 5 and the value at $60^{\circ} \mathrm{C}$ was found to be $-34.17 \mathrm{~kJ} / \mathrm{mol}$. Table 5 shows a high value of $K_{a d s}$ and the negative sign of $\Delta \mathrm{G}^{0}$ ads which indicates the, as already discussed, strong adsorption of BFC and surface of alloy. $\Delta \mathrm{G}^{\circ}$ ads values can be used to determine whether physical or chemical adsorption has occurred on the surface of the alloy. When $\Delta \mathrm{G}^{\mathrm{o}}$ ads value is less than -20 $\mathrm{kJ} / \mathrm{mol}$, physical adsorption (physisorption) is considered to be the major contributor to the adsorption process because of the Vander walls forces of attraction between the alloy and the inhibitor and when $\Delta \mathrm{G}^{\mathrm{o}}$ ads value is lesser than $-30 \mathrm{~kJ} / \mathrm{mol}$; then contribution by chemical adsorption is high. From the table it can be seen BFC shows $\Delta \mathrm{G}^{\mathrm{o}}$ ads value more negative than $-30 \mathrm{~kJ} / \mathrm{mol}$ at all temperature, so it can be seen that chemical adsorption contributes to higher percentage of adsorption of BFC on the alloy surface. At high temperature $\Delta \mathrm{G}^{\mathrm{o}}$ ads becomes more negative which suggest that chemical bond formation takes place to a larger extent at high temperature compared to low temperature.

3.7. Effect of Temperature. The effect of temperature on the inhibition action of BFC was studied at different temperature ranges from $30^{\circ} \mathrm{C}$ to $60^{\circ} \mathrm{C}$ using Tafel polarization method and EIS measurement. It was observed that change in temperature changes the rate of the corrosion and rate of adsorption

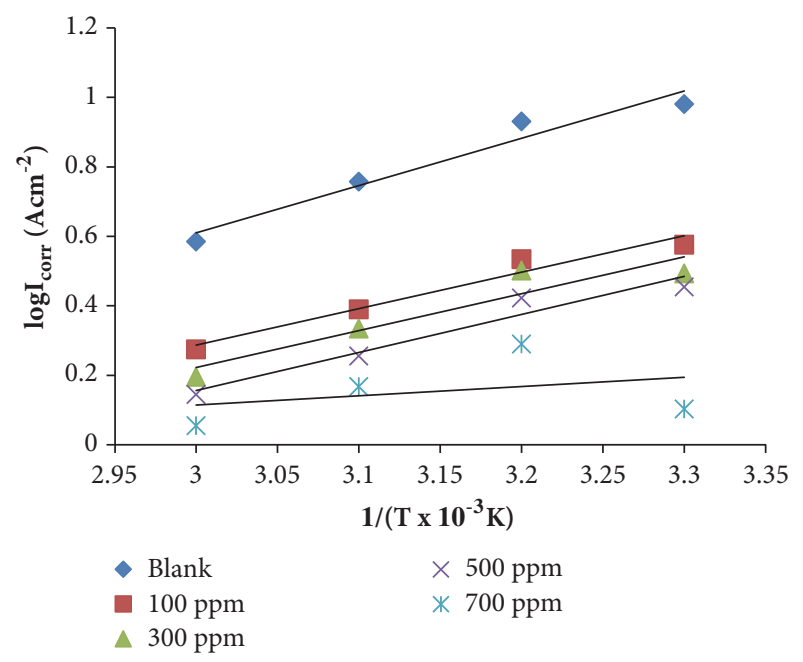

FIGURE 9: Arrhenius plot of $\log \mathrm{I}_{\text {corr }}$ versus $1 / \mathrm{T} 10^{-3}$ for the effect of temperature on the performance of $\mathrm{BFC}$ on brass in $1 \mathrm{M} \mathrm{HCl}$.

of the BFC on the alloy surface. Increase in temperature increases both the chemical adsorption and also the corrosion rate. Increase in the corrosion rate was found to be high in blank compared to the alloy in the presence of the inhibitor as a result the corrosion inhibition efficiency of the BFC increases with increase in temperature. Rapid desorption of the inhibitor, etching of metal, chemisorption of the inhibitor, decomposition of the inhibitor, and rearrangement of the inhibitor are the various process that can take place when the temperature increases. At high temperature BFC forms strong covalent coordinate bond compared to the physical adsorption which dominates at low temperature. At each temperature there is an equilibrium between the adsorption and desorption of the inhibitor on the surface of the brass alloy. When the temperature changes the equilibrium is shifted and a new equilibrium is reached, with BFC the shift in equilibrium is towards the adsorption towards the alloys and an increase in the $K$ value could be observed.

Arrhenius equation and transition state equations can be used to calculate the activation energy, enthalpy of adsorption, and entropy of adsorption The Arrhenius and transition state plots are shown in Figures 9 and 10. The equation for the calculation of activation energy and thermodynamic parameter is given in the following:

$$
\begin{aligned}
\log \left(\mathrm{I}_{\text {corr }}\right) & =\frac{-\mathrm{E}_{\mathrm{a}}}{(2.303 \mathrm{RT})}+\log \mathrm{A} \\
\mathrm{I}_{\text {corr }} & =\frac{\mathrm{RT}}{\mathrm{Nh}} \exp \left(\frac{\Delta \mathrm{S}^{*}}{\mathrm{R}}\right) \exp \left(\frac{-\Delta \mathrm{H}^{*}}{\mathrm{RT}}\right)
\end{aligned}
$$

In these equations $\mathrm{I}_{\text {corr }}$ represents the corrosion current, $\mathrm{R}$ is the universal gas constant, $\mathrm{T}$ is the absolute temperature, $\mathrm{N}$ is the Avogadro number, $\mathrm{h}$ is the plank's constant, $\Delta \mathrm{S}^{*}$ is the entropy change for the adsorption process, and $\Delta \mathrm{H}^{*}$ is the enthalpy change.

Figure 9 represents the plot of $\log \left(\mathrm{I}_{\text {corr }}\right)$ versus $1 /$ ( $\mathrm{T}$ $\mathrm{x} 10^{-3} \mathrm{~K}$ ) for blank and various concentration of inhibitors. A straight line was obtained. Slope of the plot of (18) was 


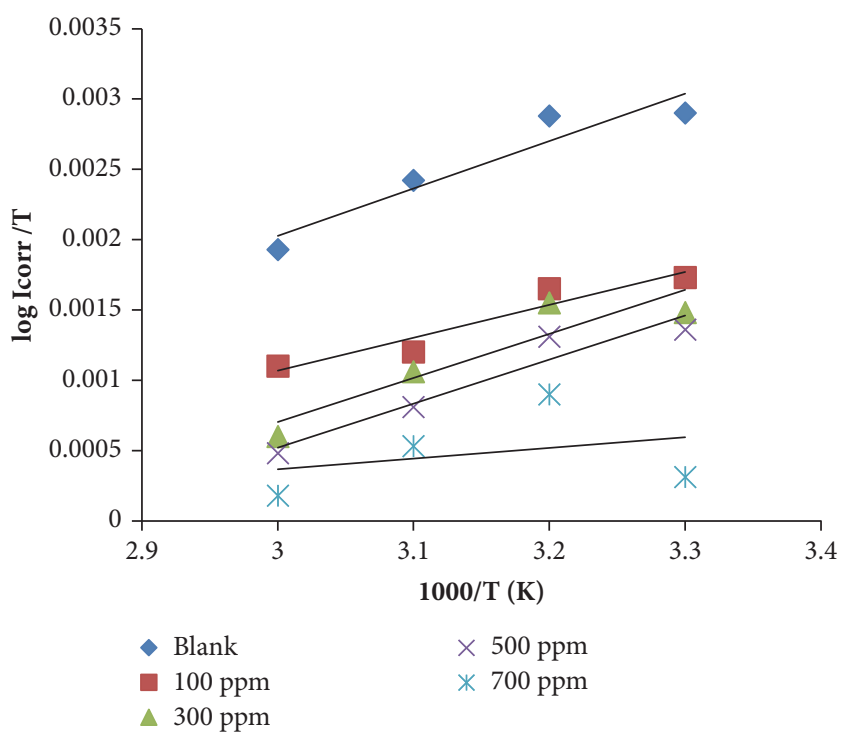

FIGURE 10: Transition state plot for brass corrosion with and without $\mathrm{BFC}$ in $1 \mathrm{M} \mathrm{HCl}$ at $60^{\circ} \mathrm{C}$

used for the calculation of $\mathrm{E}_{\mathrm{a}}$, and Table 6 shows the results. An increase in $E_{a}$ was observed when the temperature decreases. Radovici classification of the inhibitor was applied to BFC inhibition on Brass surface. Inhibitors were classified according to their behaviour at high temperature. There were three cases: when energy of activation of inhibitor is equal to energy of activation of blank, then with change in temperature there would not be any increase or decrease of inhibition. In the second case when the enthalpy of activation of the blank is greater than enthalpy of activation of inhibitor, then with increase in temperature there would be an increase in the corrosion inhibition; in the last condition when $\mathrm{E}_{\mathrm{a}}$ of the blank is less than $\mathrm{E}_{\mathrm{a}}$ of inhibitor then increase in temperature decreases the inhibition efficiency [28, 29].

BFC molecules has heteroatoms like oxygen and nitrogen which can form bonds with the brass surface and can form covalent coordinate bond. With increase in temperature the reaction rate increases as the number of covalent bond formations increases since the activation energy for the formation of the covalent bond decreases. Hence more attraction by the heteroatom of the BFC with the brass metal increases the surface coverage and decrease in the corrosion was observed.

It can be inferred from the table that the activation energy is lowest at (11.542) $700 \mathrm{ppm}$ for the adsorption of BFC on the brass surface. Table 6 shows that at the inhibitor concentration of $700 \mathrm{ppm}$ the activation energy value is the lowest which is also the optimum condition of inhibitor concentration.

The plot of $\log \left(\mathrm{I}_{\text {corr }} / \mathrm{T}\right)$ versus $1000 / \mathrm{T}$ was shown in Figure 10. $\Delta \mathrm{H}^{\mathrm{o}}$ and $\Delta \mathrm{S}^{\mathrm{O}}$ are calculated from the slope and intercept of straight line is obtained and the values are given in Table 6. $\Delta \mathrm{H}^{\mathrm{o}}$ and $\Delta \mathrm{S}^{\mathrm{o}}$ values at optimum condition of inhibitor in $1 \mathrm{M} \mathrm{HCl}$ on the brass surface $(14.93 \mathrm{~kJ} / \mathrm{mol}$ and $-139.78 \mathrm{~J} /(\mathrm{mol} \mathrm{K}))$ are less than the values in the absence of inhibitor. The desorption of the solvent molecule and the attraction of the inhibitor towards the surface of the brass makes $\Delta S^{o}$ negative because one molecule of inhibitor desorbs more than 1 molecule of the solvent. So the randomness decreases on the surface of the brass, hence decreases in entropy are observed.

3.8. Surface Analysis. The surface morphology of the corroded and inhibited brass specimen was studied by the FT-IR and SEM analysis.

3.8.1. FT-IR Analysis. The FT-IR spectrum of BFC was recorded by coating the inhibitors on the $\mathrm{KBr}$ disc. The FT-IR spectrum of the brass specimen in the presence and absence of inhibitor was immersed in $1 \mathrm{M} \mathrm{HCl}$ solution. After the elapsed time the specimens were cleaned with double distilled water and dried at room temperature with cold air. Then it is characterized by Perkin Elmer Make-Model Spectrum RX (FT-IR).

FT-IR spectrum of brass in $1 \mathrm{M} \mathrm{HCl}, \mathrm{BFC}$, and brass in $1 \mathrm{M} \mathrm{HCl}$ with BFC was shown in Figures 11(a), 4(a), and 11(b). The corresponding peak values are presented in Table 7. The broad peak at $3732.61 \mathrm{~cm}^{-1}$ is assigned to superficial absorbed water stretching mode of an $\mathrm{OH}$. The stretching frequency of secondary amine shifts from 3216.55 to 3329.56 $\mathrm{cm}^{-1}$ due to lone pair of electrons present in the nitrogen atom which coordinates with $\mathrm{Cu}^{2+}$ to form a complex. A peak between 1300 to $1602.11 \mathrm{~cm}^{-1}$ indicates the presence of secondary amide of BFC. The peak at $1032.87 \mathrm{~cm}^{-1}$ indicates the formation of complex. The peaks between the ranges of 400 to $700 \mathrm{~cm}^{-1}$ were mainly due to $\mathrm{ZnO}_{2}$ and $\mathrm{CuO}_{2}$.

3.8.2. SEM Analysis. The brass specimen was polished with various grades of emery sheet, rinsed with distilled water, degreased with acetone. The SEM images of brass were recorded using a scanning electron microscope (standard JEOL 6280 JXXA and LEO 435 VP model electron).

The surface morphology of brass sample in $1 \mathrm{M} \mathrm{HCl}$ solution in the absence and presence of BFC at optimum concentration of $1.81 \mathrm{mM}$ was shown in Figures 12(b) and 12(c). The surface of brass metal was badly damaged in $\mathrm{HCl}$ solution for 2 hours indicating that there is significant corrosion. However in presence of BFC the surface of brass is smooth, implying that the corrosion rate is controlled. This improvement in surface morphology is due to the formation of a stable protective layer of BFC on brass surface.

3.9. Quantum Chemical Calculations. To study the effect of molecular structure on inhibition efficiency, quantum chemical calculation was performed using RB3LYP/6-311G method and the calculations were carried out by the geometrical optimization of BFC. According to Fukui's frontier molecular orbital theory the ability of the inhibitor is associated with frontier molecular orbital, highest molecular orbital (HOMO), lowest unoccupied molecular orbital (LUMO), and dipole moment (I). The optimization structure of BFC, $\mathrm{E}_{\mathrm{HOMO}}, \mathrm{E}_{\mathrm{LUMO}}$, and Mulliken charges was shown in Figures 13(a), 13(b), 13(c), and 13(d). The energies of frontier orbital theory $\left(\mathrm{E}_{\mathrm{HOMO}}\right.$ and $\left.\mathrm{E}_{\mathrm{LUMO}}\right)$ are the most important parameters to predict the reactivity of chemical species. It has been observed that $\mathrm{E}_{\mathrm{HOMO}}$ is associated with electron 


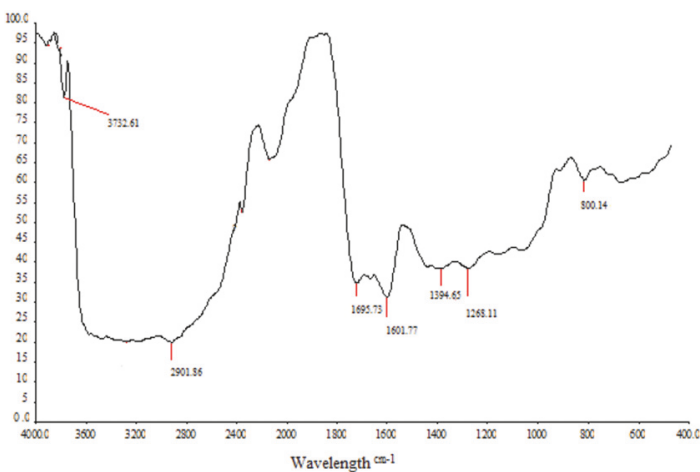

(a) FT-IR peak values of brass in $1 \mathrm{M} \mathrm{HCl}$

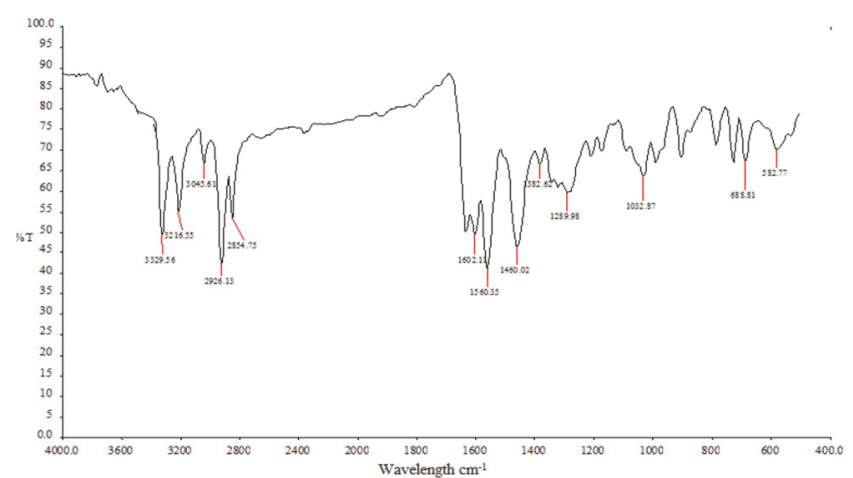

(b) FT-IR peak values of brass in $1 \mathrm{M} \mathrm{HCl}$ with BFC

Figure 11

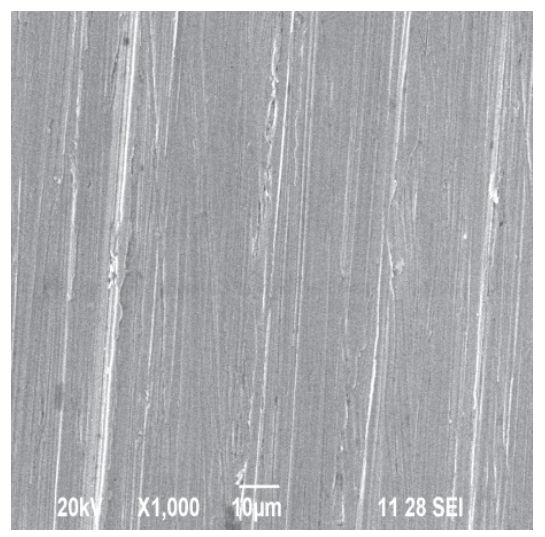

(a)

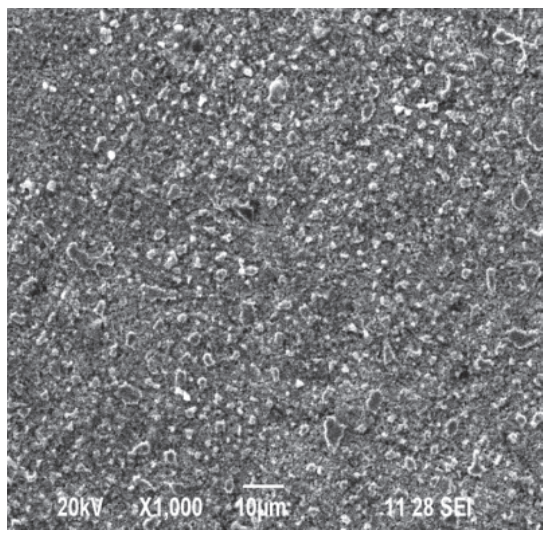

(b)

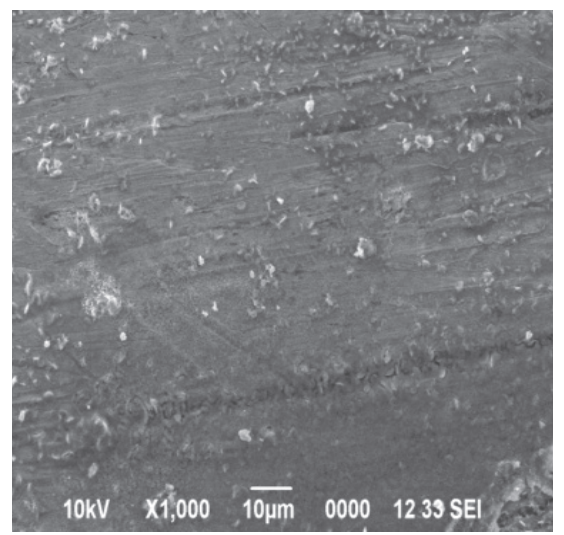

(c)

FIGURE 12: (a) SEM image of brass before immersion (polished); (b) SEM image of brass in IM HCl; (c) SEM image of brass in IM HCl with BFC.

donating ability of a molecule. The inhibition efficiency of $\mathrm{BFC}$ increases with increase in $\mathrm{E}_{\mathrm{HOMO}}$. High $\mathrm{E}_{\mathrm{HOMO}}$ value indicates that the molecule has a tendency to donate electrons to an appropriate acceptor molecule. In addition to that if the value of $\mathrm{E}_{\mathrm{LUMO}}$ is less, it easily accepts electrons from the donar molecules [30-33].

Computed parameters such as $\mathrm{E}_{\mathrm{HOMO}}, \mathrm{E}_{\mathrm{LUMO}}$, energy gap $\left(\Delta \mathrm{E}=\mathrm{E}_{\mathrm{LUMO}}-\mathrm{E}_{\mathrm{HOMO}}\right)$, dipole moment $(\mu)$, absolute electronegativity $(\chi)$, global hardness $(\eta)$, and global softness $(\sigma)$ were calculated and shown in Table 5. To calculate the quantum chemical parameters $\chi$ and $\eta$ the following equation was used [34-36]:

$$
\begin{aligned}
& \chi=\frac{\mathrm{E}_{\mathrm{LUMO}}+\mathrm{E}_{\mathrm{HOMO}}}{2} \\
& \eta=\frac{\mathrm{E}_{\mathrm{LUMO}}-\mathrm{E}_{\mathrm{HOMO}}}{2}
\end{aligned}
$$

The inverse of global hardness $(\eta)$ is designated as global softness $(\sigma)$ and it is calculated by the following equation.
By calculating these hardness and softness properties, the stability and reactivity of inhibitor molecule are measured:

$$
\sigma=\frac{1}{\eta}
$$

The energy band gap between $\mathrm{E}_{\mathrm{HOMO}}$ and $\mathrm{E}_{\mathrm{LUMO}}(\Delta \mathrm{E})$ of the molecule is used to expand theoretical models that are qualitatively able to explain the structure and conformation barriers in molecular system. Hard molecule has large energy gap, whereas soft molecule has low gap. Soft molecules are more reactive than hard ones due to the donation of electrons to the acceptors. It is eminent that smaller the value of $\Delta \mathrm{E}$ of an inhibitor, the higher the inhibition efficiency of molecule $[37,38]$.

From Table 8 it is obvious that $\mathrm{BFC}$ has higher $\mathrm{E}_{\mathrm{HOMO}}$ value $(-0.0627 \mathrm{eV})$ which indicates that it donates electrons and the value of $\mathrm{E}_{\mathrm{LUMO}}$ is less $(-0.0282 \mathrm{eV})$ which implies that it accepts the electrons. The energy band gap value for $\mathrm{BFC}$ is low $(0.0345 \mathrm{eV})$ due to the stable nature on the metal surface which affirmed the corrosion resistance of brass in $1 \mathrm{M} \mathrm{HCl}$. The dipole moment $(\mu)$ value of $\mathrm{BFC}$ is 4.9349 which is bigger 


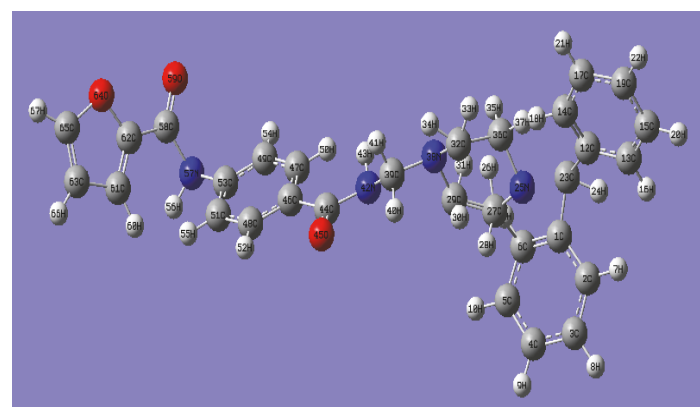

(a) Optimized molecular structure of BFC

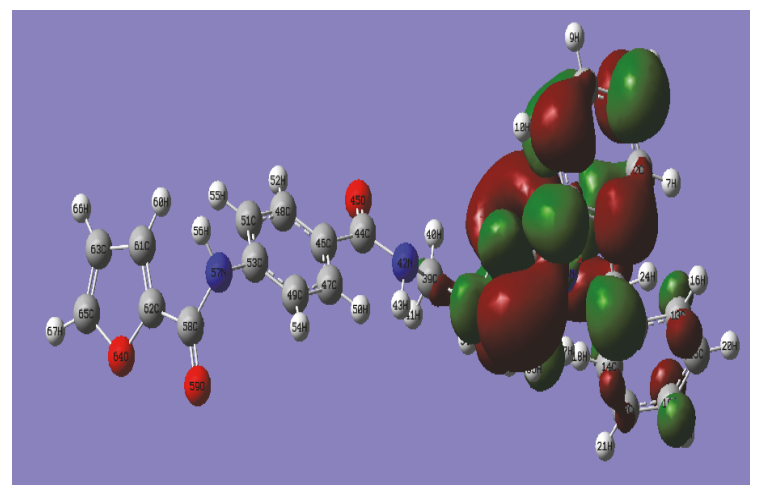

(c) Frontier molecular orbital density distribution of BFC (LUMO)

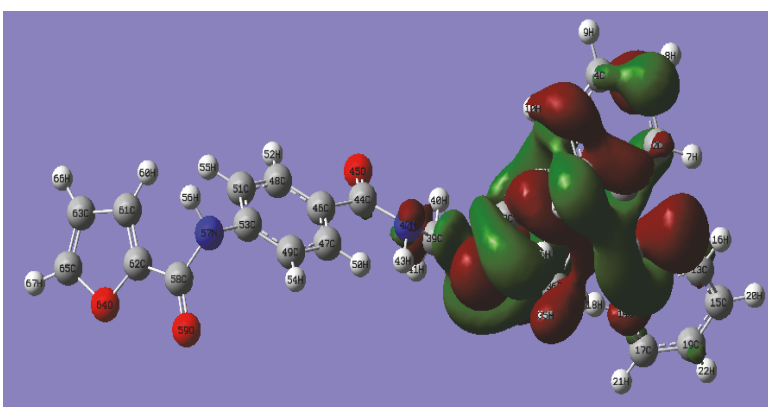

(b) Frontier molecular orbital density distribution of BFC (HOMO)

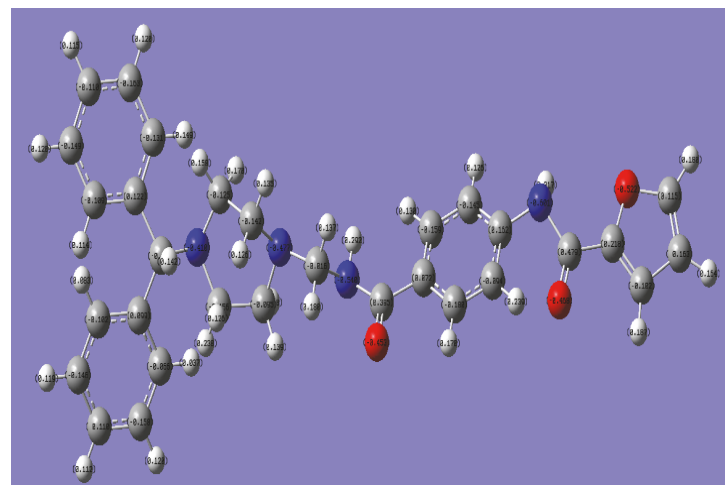

(d) Mulliken charges for BFC molecule

Figure 13

TABLE 6: Thermodynamic parameters for corrosion of brass in $1 \mathrm{M} \mathrm{HCl}$ with BFC.

\begin{tabular}{|c|c|c|c|c|c|c|c|c|}
\hline \multirow{2}{*}{ Concentration (ppm) } & \multirow{2}{*}{$\mathrm{E}_{\mathrm{a}}(\mathrm{kJ} / \mathrm{mol})$} & \multirow{2}{*}{$\mathrm{A}\left(\mathrm{A} / \mathrm{cm}^{2}\right)$} & \multirow{2}{*}{$\Delta \mathrm{H}^{\mathrm{o}}(\mathrm{kJ} / \mathrm{mol})$} & \multirow{2}{*}{$\Delta \mathrm{S}^{\mathrm{o}}(\mathrm{J} / \mathrm{K} . \mathrm{mol})$} & \multicolumn{4}{|c|}{$\Delta \mathrm{G}^{\mathrm{o}}(\mathrm{kJ} / \mathrm{mol})$} \\
\hline & & & & & 303 & 313 & 323 & 333 \\
\hline Blank & 32.824 & 157.20 & 20.71 & -110.221 & 51.07 & 52.07 & 53.07 & 54.08 \\
\hline 100 & 24.695 & 11.16 & 16.56 & -128.532 & 51.97 & 53.14 & 54.31 & 55.48 \\
\hline 300 & 20.152 & 10.20 & 15.75 & -133.615 & 52.55 & 53.77 & 54.98 & 56.20 \\
\hline 500 & 15.974 & 8.27 & 15.06 & -137.39 & 52.90 & 54.15 & 55.40 & 56.65 \\
\hline 700 & 11.542 & 6.11 & 14.93 & -139.779 & 53.43 & 54.70 & 55.97 & 57.24 \\
\hline
\end{tabular}

than the dipole moment of water (1.88 Debye), indicating that there is a strong dipole-dipole interaction between the inhibitor molecule and brass surface. Molecule exhibiting lower energy difference $(\Delta \mathrm{E})$ value readily undergoes charge transfer interface on the metal surface, thereby increasing the inhibition efficiency [39-42].

In this present work the value of $\sigma$ is (58.13) high, thereby increasing the inhibition efficiency of BFC, which is in good agreement compared with experimental values. The absolute electronegativity $(\chi)$ and global electrophilicity $(\omega)$ of BFC were 0.0454 and 0.2094 which indicated the stability and reactivity of inhibitor molecule.

The adsorption centers of inhibitor molecules were analysed by using Mulliken charges. The Mulliken charges of BFC molecule reveal that the heteroatom $(\mathrm{N})$ has more negative charge compared with other atoms, which implies that the adsorption of brass metal is due to the electron donation of an electronegative atom $(\mathrm{N})$ to the metal surface.

\section{Conclusions}

The structure of the synthesized compound BFC was confirmed by spectral data. Weight loss measurement indicates that the inhibition efficiency of BFC increases with an increase in concentration and temperature ranges from $30^{\circ} \mathrm{C}$ to $60^{\circ} \mathrm{C}$. Polarization measurements imply that BFC acts as a mixed type inhibitor, and it controls both hydrogen evolution and metal dissolution process. The inhibition efficiency of BFC obtained from AC impedance is in good agreement compared with the conventional weight loss and polarization methods.

Cyclic voltammetry study reveals that the addition of inhibitor reduces the oxidation of copper on the surface of brass. Adsorption isotherm shows that BFC obeys Langmuir adsorption isotherm and the reaction is exothermic. The inhibition efficiency of BFC was closely related to quantum chemical parameters. The purity of the inhibitor was confirmed by LC-MS. 
TABLE 7: FT-IR analysis of brass in $1 \mathrm{M} \mathrm{HCl}, \mathrm{BFC}$, and brass in $1 \mathrm{M} \mathrm{HCl}$ with BFC.

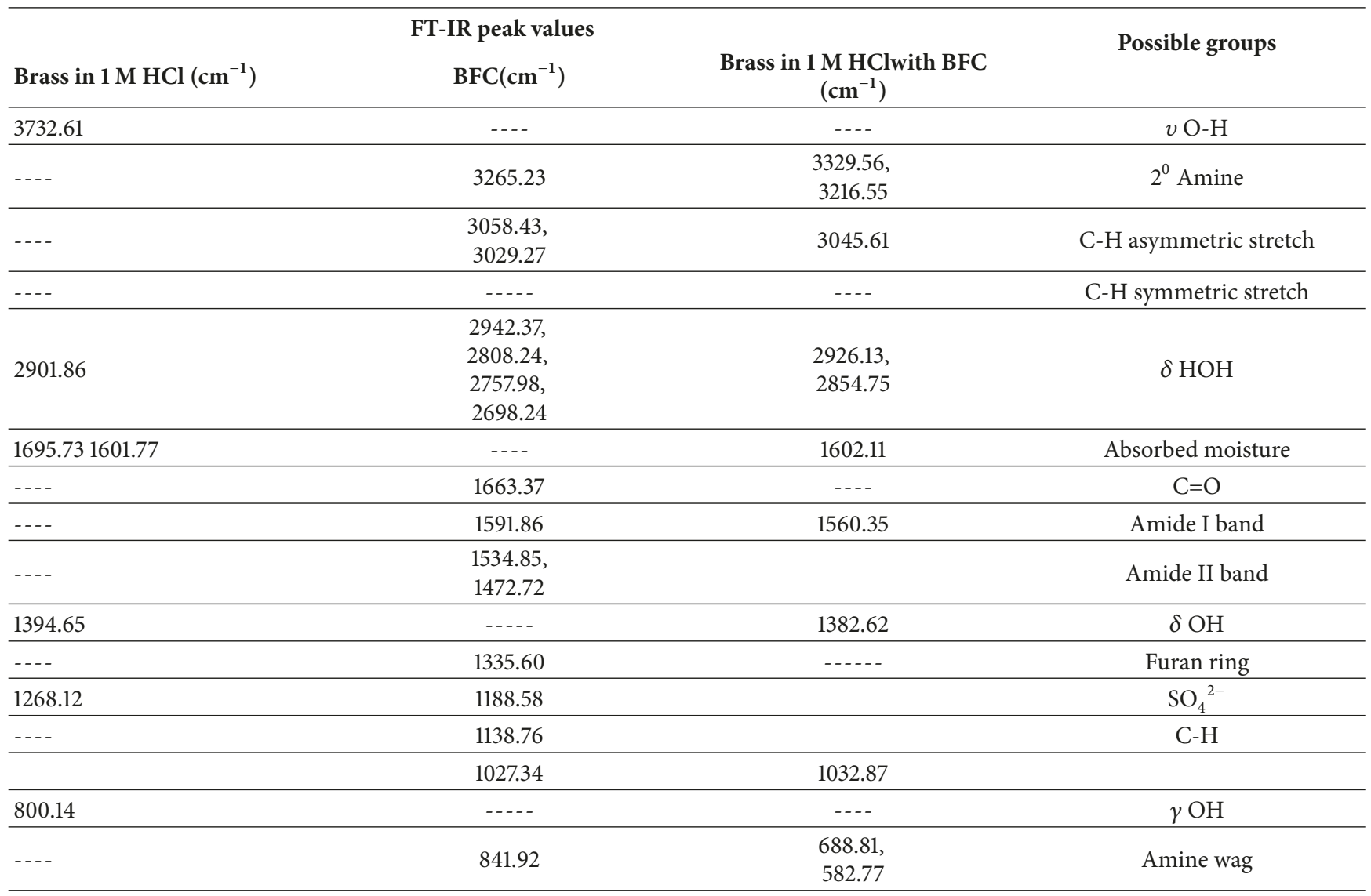

TABLE 8: Quantum chemical parameters for BFC.

\begin{tabular}{lcccccccc}
\hline Inhibitor & $\mathrm{E}_{\text {Hомо }}(\mathrm{eV})$ & $\mathrm{E}_{\mathrm{LUMO}}(\mathrm{eV})$ & $\Delta \mathrm{E}(\mathrm{eV})$ & $\mu(\mathrm{D})$ & $\eta(\mathrm{eV})$ & $\sigma(\mathrm{eV})$ & $\chi$ & $\omega$ \\
$\mathrm{BFC}$ & -0.0627 & -0.0282 & 0.0345 & 4.9349 & 0.0172 & 58.13 & 0.0454 & 0.2094 \\
\hline
\end{tabular}

\section{Data Availability}

The data used to support the findings of this study are available from the corresponding author upon request.

\section{Conflicts of Interest}

The authors declare that there are no conflicts of interest regarding the publication of this paper.

\section{References}

[1] J. R. Xavier, S. Nanjundan, and N. Rajendran, "Electrochemical Adsorption Properties and Inhibition of Brass Corrosion in Natural Seawater by Thiadiazole Derivatives: Experimental and Theoretical Investigation," Industrial \& Engineering Chemistry Research, vol. 51, no. 1, pp. 30-43, 2011.

[2] A. K. Singh, M. A. Quraishi, and E. E. Ebenso, "Inhibitive effect of cefuroxime on the corrosion of mild steel in hydrochloric acid solution," International Journal of Electrochemical Science, vol. 6, no. 11, pp. 5676-5688, 2011.

[3] V. P. Singh, P. Singh, and A. K. Singh, "Synthesis, structural and corrosion inhibition studies on cobalt(II), nickel(II), copper(II) and zinc(II) complexes with 2-acetylthiophene benzoylhydrazone," Inorganica Chimica Acta, vol. 379, no. 1, pp. 56-63, 2011.

[4] Nagham, Mahmood, and Aljamali, "Synthesis and Characterization of Fused Rings from Mannich Bases," Journal of KerbalaUniversity, vol. 11, 2 pages, 2013.

[5] D. Karthik, D. Tamilvendan, and G. Venkatesa Prabhu, "Study on the inhibition of mild steel corrosion by 1,3-bis-(morpholin4-yl-phenyl-methyl)-thiourea in hydrochloric acid medium," Journal of Saudi Chemical Society, vol. 18, no. 6, pp. 835-844, 2014.

[6] P. Preethi Kumari, P. Shetty, and S. A. Rao, "Electrochemical measurements for the corrosion inhibition of mild steel in $1 \mathrm{M}$ hydrochloric acid by using an aromatic hydrazide derivative," Arabian Journal of Chemistry, vol. 10, no. 5, pp. 653-663, 2017.

[7] A. Y. Musa, A. A. H. Kadhum, A. B. Mohamad, A. R. Daud, M. S. Takriff, and S. K. Kamarudin, "A comparative study of the corrosion inhibition of mild steel in sulphuric acid by 4,4dimethyloxazolidine-2-thione," Corrosion Science, vol. 51, no. 10, pp. 2393-2399, 2009.

[8] S. Pooja, R. K. Upadyay, and C. Alok, "A comparative study of corrosion inhibitive efficiency of some newly synthesized Mannich bases with their parent amine for $\mathrm{Al}$ in $\mathrm{HCl}$ solution," 
Research Journal of Chemical Sciences, vol. 1, no. 5, pp. 29-35, 2011.

[9] K. F. Khaled, S. S. Abdel-Rehim, and G. B. Sakr, "On the corrosion inhibition of iron in hydrochloric acid solutions, Part I: Electrochemical DC and AC studies," Arabian Journal of Chemistry, vol. 5, no. 2, pp. 213-218, 2012.

[10] K. F. Khaled and A. El-Maghraby, "Experimental, Monte Carlo and molecular dynamics simulations to investigate corrosion inhibition of mild steel in hydrochloric acid solutions," Arabian Journal of Chemistry, vol. 7, no. 3, pp. 319-326, 2014.

[11] R. V. Saliyan and A. V. Adhikari, "Corrosion inhibition of mild steel in acid media by quinolinyl thiopropano hydrazone," Indian Journal of Chemical Technology, vol. 16, no. 2, pp. 162-174, 2009.

[12] E. M. Sherif, R. M. Erasmus, and J. D. Comins, "Inhibition of copper corrosion in acidic chloride pickling solutions by 5 (3-aminophenyl)-tetrazole as a corrosion inhibitor," Corrosion Science, vol. 50, no. 12, pp. 3439-3445, 2008.

[13] A. K. Singh, "Inhibition of mild steel corrosion in hydrochloric acid solution by 3-(4-((Z)-indolin-3-ylideneamino)phenylimino)indolin-2-one," Industrial \& Engineering Chemistry Research, vol. 51, no. 8, pp. 3215-3223, 2012.

[14] G. Quartarone, L. Bonaldo, and C. Tortato, "Inhibitive action of indole-5-carboxylic acid towards corrosion of mild steel in deaerated $0.5 \mathrm{M}$ sulfuric acid solutions," Applied Surface Science, vol. 252, no. 23 , pp. 8251-8257, 2006.

[15] S. T. Selvi, V. Raman, and N. Rajendran, "Corrosion inhibition of mild steel by benzotriazole derivatives in acidic medium," Journal of Applied Electrochemistry, vol. 33, no. 12, pp. 1175-1182, 2003.

[16] . Sudheer and M. Quraishi, "Electrochemical and theoretical investigation of triazole derivatives on corrosion inhibition behavior of copper in hydrochloric acid medium," Corrosion Science, vol. 70, pp. 161-169, 2013.

[17] C. M. A. Brett, "On the electrochemical behaviour of aluminium in acidic chloride solution," Corrosion Science, vol. 33, no. 2, pp. 203-210, 1992.

[18] N. Fishelson, A. Inberg, N. Croitoru, and Y. Shacham-Diamand, "Highly corrosion resistant bright silver metallization deposited from a neutral cyanide-free solution," Microelectronic Engineering, vol. 92, pp. 126-129, 2012.

[19] M. Lebrini, M. Lagrenée, H. Vezin, M. Traisnel, and F. Bentiss, "Experimental and theoretical study for corrosion inhibition of mild steel in normal hydrochloric acid solution by some new macrocyclic polyether compounds," Corrosion Science, vol. 49, no. 5, pp. 2254-2269, 2007.

[20] W. Chen, S. Hong, H. B. Li, H. Q. Luo, M. Li, and N. B. Li, "Protection of copper corrosion in $0.5 \mathrm{M} \mathrm{NaCl}$ solution by modification of 5-mercapto-3-phenyl-1,3,4-thiadiazole-2-thione potassium self-assembled monolayer," Corrosion Science, vol. 61, pp. 53-62, 2012.

[21] I. Ahamad, R. Prasad, and M. A. Quraishi, "Adsorption and inhibitive properties of some new Mannich bases of Isatin derivatives on corrosion of mild steel in acidic media," Corrosion Science, vol. 52, no. 4, pp. 1472-1481, 2010.

[22] D. D. Macdonald, "Review of mechanistic analysis by electrochemical impedance spectroscopy," Electrochimica Acta, vol. 35, no. 10, pp. 1509-1525, 1990.

[23] Akabueze and A. U. Itodo, "Inhibotary action of 1-phenyl3-methylpyrazol-5-one(HPMP) and 1-phenyl-3-methyl-4-(pnitrobenzoyl)-pyrazol-5-one(HPMNP) on the corrosion of
Alpha and Beta brass in $\mathrm{HCl}$ solution," American Journal of chemistry, vol. 2, no. 3, pp. 142-149, 2012.

[24] S. K. Bag, S. B. Chakraborty, A. Roy, and S. R. Chaudhuri, "2aminobenzimidazole as corrosion inhibitor for 70-30 brass in ammonia," British Corrosion Journal, vol. 31, no. 3, pp. 207-212, 1996.

[25] R. Ravichandran, S. Nanjundan, and N. Rajendran, "Effect of benzotriazole derivatives on the corrosion and dezincification of brass in neutral chloride solution," Journal of Applied Electrochemistry, vol. 34, no. 11, pp. 1171-1176, 2004.

[26] L. C. Murulana, M. M. Kabanda, and E. E. Ebenso, "Experimental and theoretical studies on the corrosion inhibition of mild steel by some sulphonamides in aqueous $\mathrm{HCl}$," RSC Advances, vol. 5, no. 36, pp. 28743-28761, 2015.

[27] A. Ehsani, M. G. Mahjani, R. Moshrefi, H. Mostaanzadeh, and J. S. Shayeh, "Electrochemical and DFT study on the inhibition of $316 \mathrm{~L}$ stainless steel corrosion in acidic medium by 1-(4nitrophenyl)-5-amino-1H-tetrazole," RSC Advances, vol. 4, no. 38, pp. 20031-20037, 2014.

[28] S. Shahabi, P. Norouzi, and M. R. Ganjali, "Theoretical and electrochemical study of carbon steel corrosion inhibition in the presence of two synthesized schiff base inhibitors: Application of fast Fourier transform continuous cyclic voltammetry to study the adsorption behavior," International Journal of Electrochemical Science, vol. 10, no. 3, pp. 2646-2662, 2015.

[29] V. S. Sastri, M. Elboujdaini, and J. R. Perumareddi, "Utility of quantum chemical parameters in the rationalization of corrosion inhibition efficiency of some organic inhibitors," Corrosion, vol. 61, no. 10, pp. 933-942, 2005.

[30] S. Xia, M. Qiu, L. Yu, F. Liu, and H. Zhao, "Molecular dynamics and density functional theory study on relationship between structure of imidazoline derivatives and inhibition performance," Corrosion Science, vol. 50, no. 7, pp. 2021-2029, 2008.

[31] E. E. Ebenso, T. Arslan, F. Kandemirli, N. Caner, and I. Love, "Quantum chemical studies of some rhodanine azosulpha drugs as corrosion inhibitors for mild steel in acidic medium," International Journal of Quantum Chemistry, vol. 110, no. 5, pp. 1003-1018, 2010.

[32] V. S. Sastri and J. R. Perumareddi, "Molecular orbital theoretical studies of some organic corrosion inhibitors," Corrosion, vol. 53, no. 8, pp. 617-622, 1997.

[33] I. Lukovits, E. Klaman, and F. Zucchi, "Correlation between electronic structure and efficiency," Corrosion, vol. 53, pp. 617622, 2001.

[34] R. G. Pearson, "Absolute electronegativity and hardness: applications to organic chemistry," The Journal of Organic Chemistry, vol. 54, no. 6, pp. 1423-1430, 1989.

[35] O. Blajiev and A. Hubin, "Inhibition of copper corrosion in chloride solutions by amino-mercapto-thiadiazol and methyl-mercapto-thiadiazol: An impedance spectroscopy and a quantum-chemical investigation," Electrochimica Acta, vol. 49, no. 17-18, pp. 2761-2770, 2004.

[36] A. Kokalj, "On the HSAB based estimate of charge transfer between adsorbates and metal surfaces," Chemical Physics, vol. 393, no. 1, pp. 1-12, 2012.

[37] N. Khalil, "Quantum chemical apporach of corrosion inhibition," Electrochimica Acta, vol. 48, pp. 2635-2640, 2003.

[38] G. Gece, "The use of quantum chemical methods in corrosion inhibitior studies," Corrosion Science, vol. 50, pp. 2981-2992, 2008. 
[39] M. Yadav, D. Behera, S. Kumar, and R. R. Sinha, "Experimental and quantum chemical studies on the corrosion inhibition performance of benzimidazole derivatives for mild steel in HCl," Industrial \& Engineering Chemistry Research, vol. 52, no. 19, pp. 6318-6328, 2013.

[40] M. A. Quraishi, A. Singh, V. K. Singh, D. K. Yadav, and A. K. Singh, "Green approach to corrosion inhibition of mild steel in hydrochloric acid and sulphuric acid solutions by the extract of Murraya koenigii leaves," Materials Chemistry and Physics, vol. 122, no. 1, pp. 114-122, 2010.

[41] R. Ganapathi Sundaram and M. Sundaravadivelu, "Surface protection of mild steel in acidic chloride solution by 5 -Nitro-8Hydroxy Quinoline," Egyptian Journal of Petroleum, vol. 27, no. 1, pp. 95-103, 2018.

[42] S. K. Saha, M. Murmu, N. C. Murmu, I. Obot, and P. Banerjee, "Molecular level insights for the corrosion inhibition effectiveness of three amine derivatives on the carbon steel surface in the adverse medium: A combined density functional theory and molecular dynamics simulation study," Surfaces and Interfaces, vol. 10, pp. 65-73, 2018. 


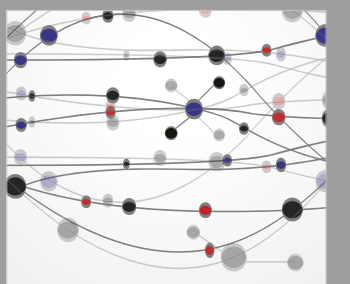

The Scientific World Journal
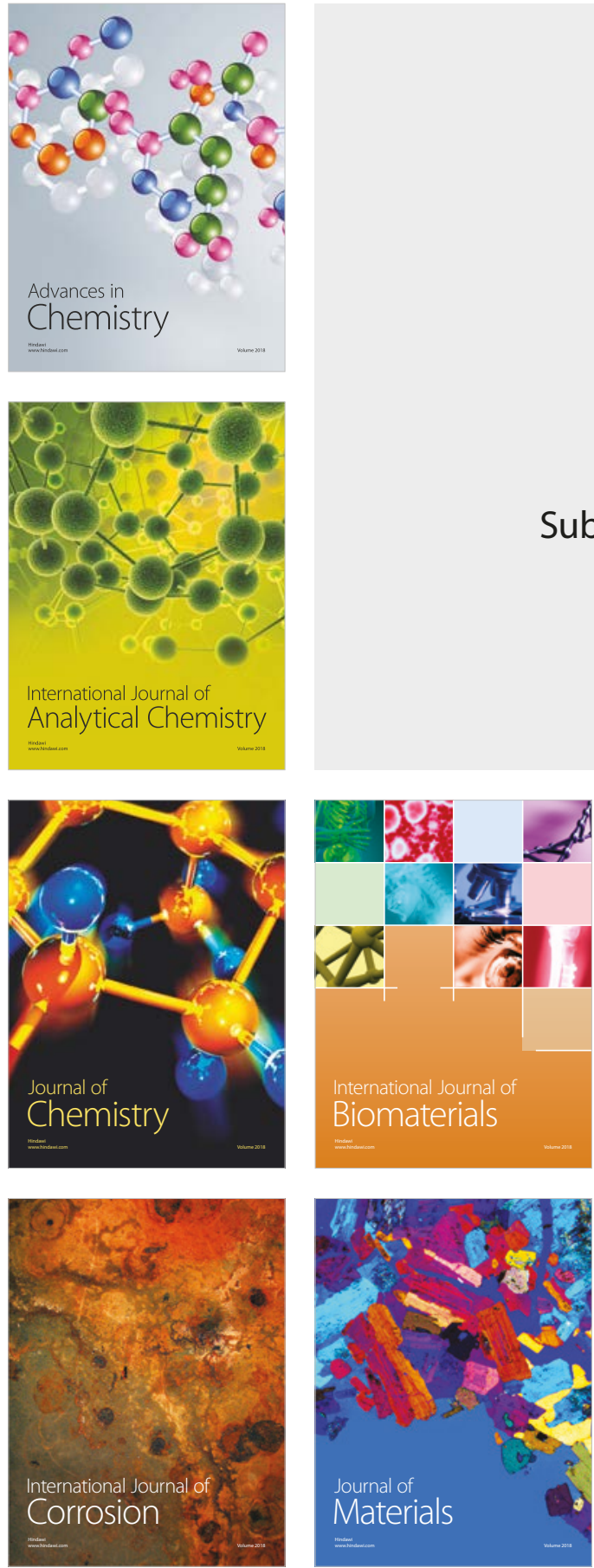

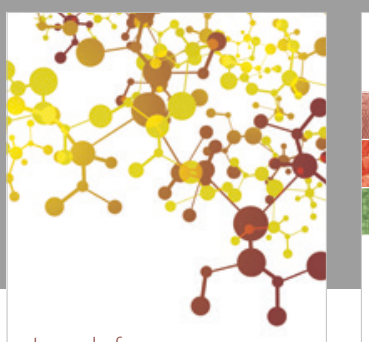

Journal of

Applied Chemistry
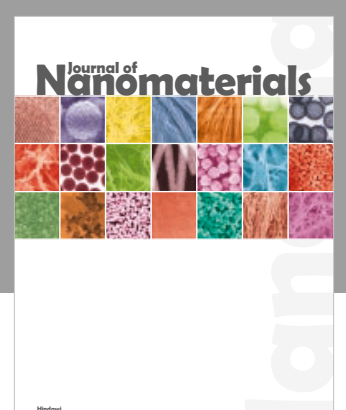

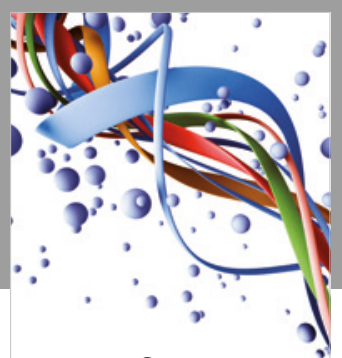

Scientifica

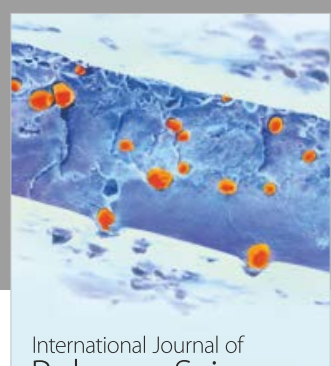

Polymer Science

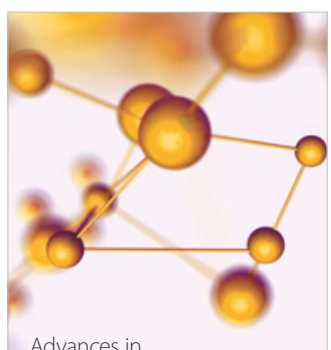

Physical Chemistry
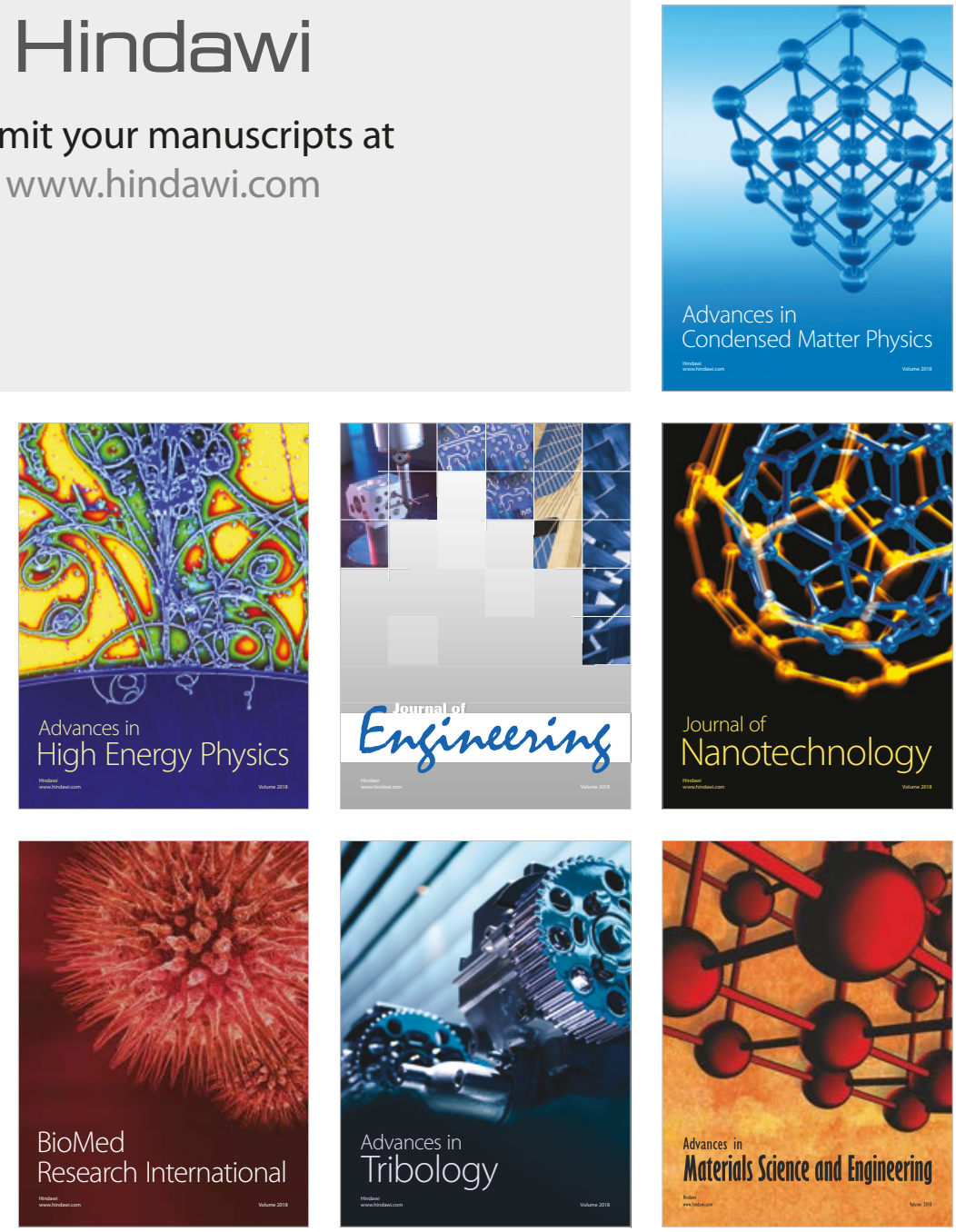